\title{
Analytical Solution for One-Dimensional Nonlinear Consolidation of Saturated Double-Layered Soil Subjected to Cyclic Loadings
}

\author{
Pyol Kim (D, Chol-U Pak, and Hakbom Myong \\ Faculty of Geology, Kim Il Sung University, Pyongyang 999093, Democratic People’s Republic of Korea \\ Correspondence should be addressed to Pyol Kim; 18846415254@163.com
}

Received 11 February 2021; Revised 17 August 2021; Accepted 22 October 2021; Published 9 November 2021

Academic Editor: Francesco Colangelo

Copyright (c) 2021 Pyol Kim et al. This is an open access article distributed under the Creative Commons Attribution License, which permits unrestricted use, distribution, and reproduction in any medium, provided the original work is properly cited.

\begin{abstract}
Cyclic loading-induced consolidation behavior of soft soil is of great interest for the analysis of offshore and onshore structures. In this study, an analytical solution for one-dimensional (1D) nonlinear consolidation of saturated double-layered soil under various types of cyclic loadings such as trapezoidal cyclic loading, rectangular cyclic loading, and triangular cyclic loading was derived. The proposed solution was subsequently degenerated into solutions for special cases and compared to the existing solutions. The degenerate solutions show good agreement with the existing results, which proves that the proposed solutions are more general ones for 1D nonlinear consolidation of saturated soils under time-dependent loading. Finally, a comprehensive parametric study was conducted to investigate the influences of different layer parameters, drainage conditions, and loading parameters on nonlinear consolidation of saturated double-layered soil under cyclic loadings.
\end{abstract}

\section{Introduction}

Soft soil beneath most of the marine structures is saturated and can be subjected to various types of cyclic loads. The sources of cyclic load include traffic loads on roads, highways, railways, and airports; silos or tanks filling and discharging; wave and wind actions for offshore structures; and so on. For those structures built on soft soil, predicting the cyclic loading-induced consolidation deformation is a very important design issue.

Up to the present, a number of methods have been proposed for consolidation analysis of saturated soil subjected to cyclic loadings, which can generally be divided into two categories according to the adopted main assumptions. Many scholars have presented different solutions for a consolidation of saturated soil under various cyclic loadings such as rectangular cyclic loading [1], haversine cyclic loading [2-4], and the other types of cyclic loadings $[5,6]$. However, those solutions are based on the linear assumption that the compressibility and the permeability of soil are constant during the consolidation process, which is a wellknown drawback of the linear consolidation theory. In order to overcome this shortcoming, a number of studies have been performed to consider nonlinear consolidation characteristics of soft soil. Several investigators $[7,8]$ analysed 1D nonlinear consolidation of soil subjected to rectangular cyclic loading using superimposing rule. In addition, numerous researchers have employed the nonlinear assumption proposed by Davis and Raymond [9] and studied the nonlinear consolidation of soil under different types of cyclic loadings [10-13]. Furthermore, Geng et al. [14], Cai et al. [15], and Kim et al. [16] developed solutions for 1D nonlinear consolidation of saturated soil subjected to cyclic loading by considering the variable consolidation coefficient.

All the research works mentioned above only considered the single-layer soil and did not take the layered characteristics of soil into consideration. In view of this, a number of researchers made great contributions to the consolidation theories of saturated layered soil in recent years [17-24]. Among them, $\mathrm{Hu}$ et al. [24] applied the differential quadrature method to analyse cyclic loading-induced nonlinear consolidation behavior of saturated multi-layered soil. However, due to the complexity of the nonlinear 
consolidation equation, none of the researchers have ever derived any analytical solutions for 1D nonlinear consolidation of soil taking both the layered characteristics of soil and the cyclic loading condition into account.

In this paper, analytical solutions are derived for $1 \mathrm{D}$ nonlinear consolidation of saturated double-layered soil under different cyclic loadings such as trapezoidal cyclic loading, rectangular cyclic loading, and triangular cyclic loading. The proposed solutions are degenerated into existing solutions in previous literature. A comprehensive parametric study is conducted to investigate the influences of different layer parameters, drainage conditions, and loading parameters on nonlinear consolidation behavior of saturated double-layered soil under cyclic loadings.

\section{Mathematical Model}

Figure 1 illustrates the schematic model for 1D nonlinear consolidation of double-layered soil subjected to time-dependent loading, where $h_{i}, k_{v 0}^{i}, m_{v 0}^{i}$, and $c_{v}^{i}$ are the thickness, the initial coefficient of permeability, the initial coefficient of compressibility, and the consolidation coefficient of the $i$-th soil layer $(i=1,2)$, respectively. $H$ is the total thickness of soil that satisfies $H=h_{1}+h_{2} . q(t)$ is the uniformly distributed timedependent loading applied on the top surface of the soil.

Based on Davis and Raymond's nonlinear consolidation theory, the governing equation for 1D nonlinear consolidation of double-layered soil subjected to time-dependent loading can be written as follows:

$$
c_{v}^{i}\left[\frac{\partial^{2} u_{i}}{\partial z^{2}}+\frac{1}{\sigma^{\prime i}}\left(\frac{\partial u_{i}}{\partial z}\right)^{2}\right]=\frac{\partial u_{i}}{\partial t}-\frac{\mathrm{d} q}{\mathrm{~d} t}, \quad i=1,2
$$

where $u_{i}$ and $\sigma^{\prime i}$ are the excess pore water pressure and the effective vertical stress in the $i$-th soil layer, respectively; $z$ is the spatial coordinate as shown in Figure 1; and $t$ is time.

According to the assumption that the decrease in permeability is proportional to the decrease in compressibility during the consolidation process of soil, the consolidation coefficient $c_{v}^{i}$ is given by $c_{v}^{i}=\left(k_{v 0}^{i} / m_{v 0}^{i} \gamma_{w}\right)$, in which $\gamma_{w}$ is the unit weight of water; $m_{v 0}^{i}=0.434 C_{v}^{i} /\left(1+e_{0}^{i}\right) / \sigma_{0}^{\prime i}$, where $C_{c}^{i}$ and $e_{0}^{i}$ are the compression index and the initial void ratio in the $i$-th layer corresponding to the initial effective vertical stress $\sigma_{0}^{\prime i}$, respectively. By the assumption that the distribution of initial effective stress is constant with depth, $\sigma_{0}^{\prime i}=\sigma_{0}^{\prime}$.

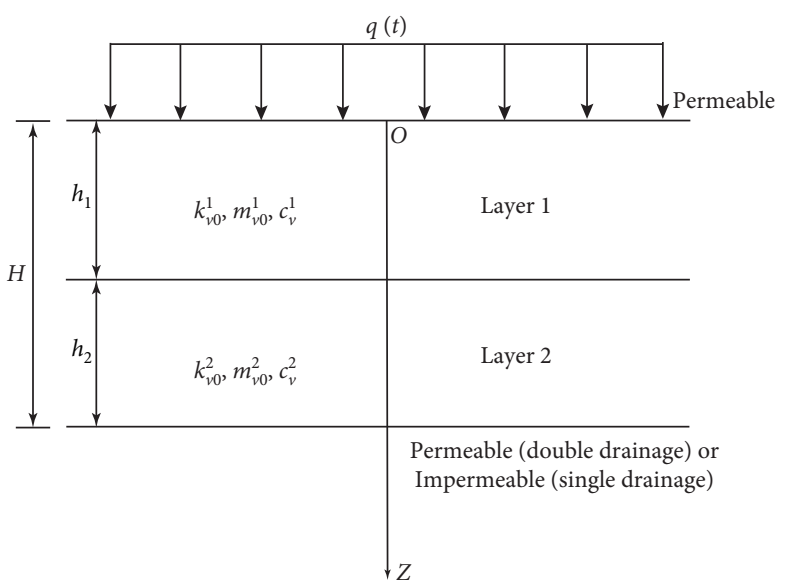

Figure 1: Schematic model of double-layered soil.

Using Terzaghi's principle of effective stress, $\sigma^{\prime i}$ can be written as follows:

$$
\sigma^{\prime i}=\sigma_{0}^{\prime}+q-u_{i}
$$

In order to simplify equation (1), a new variable can be defined as follows:

$$
\omega_{i}=\ln \left(\frac{\sigma^{\prime i}}{\sigma_{0}^{\prime}+q}\right) .
$$

Then, equation (1) can be simplified in terms of $\omega_{i}$ as follows:

$$
\frac{\partial \omega_{i}}{\partial t}=c_{v}^{i} \frac{\partial^{2} \omega_{i}}{\partial z^{2}}+R(t), \quad i=1,2
$$

where

$$
R(t)=-\frac{1}{\sigma_{0}^{\prime}+q} \frac{\mathrm{d} q}{\mathrm{~d} t} .
$$

The initial condition for equation (4) in terms of $u_{i}$ and $\omega_{i}$ can be given by

$$
u_{i}(z, 0)=q(0) \text {, or } \omega_{i}(z, 0)=\omega_{0} .
$$

The boundary conditions in terms of $u_{i}$ and $\omega_{i}$ can be written as follows:

$$
\begin{aligned}
u_{1}(0, t) & =0, \text { or } \omega_{1}(0, t)=0 \\
\frac{\partial u_{2}(H, t)}{\partial z} & =0, \text { or } \frac{\partial \omega_{2}(H, t)}{\partial z}=0, \quad \text { (for single drainage condition), } \\
u_{2}(H, t) & =0, \text { or } \omega_{2}(H, t)=0, \quad \text { (for double drainage condition) } \\
u_{1}\left(h_{1}, t\right) & =u_{2}\left(h_{1}, t\right), \text { or } \omega_{1}\left(h_{1}, t\right)=\omega_{2}\left(h_{1}, t\right) \\
k_{v}^{i} \frac{\partial u_{1}\left(h_{1}, t\right)}{\partial z} & =k_{v}^{2} \frac{\partial u_{2}\left(h_{1}, t\right)}{\partial z}, \text { or } \frac{\partial \omega_{1}\left(h_{1}, t\right)}{\partial z}=K \frac{\partial \omega_{2}\left(h_{1}, t\right)}{\partial z}
\end{aligned}
$$


where $\omega_{0}=\ln \left\{\sigma_{0}^{\prime} /\left[\sigma_{0}^{\prime}+q(0)\right]\right\}$ and $K=k_{v}^{2} / k_{v}^{1}=c_{v}^{2} m_{v 0}^{2} / c_{v}^{1} m_{v 0}^{1}$ $=k_{v 0}^{2} / k_{v 0}^{1}$.

\section{Derivation of Solutions for Cyclic Loadings}

\subsection{Solutions for Trapezoidal Cyclic Loading}

3.1.1. Excess Pore Water Pressure. From equations (2) and (3), the excess pore water pressure for double-layered soil subjected to time-dependent loading can be written as follows:

$$
u_{i}=\left(\sigma_{0}^{\prime}+q\right)\left(1-e^{\omega_{i}}\right), \quad i=1,2,
$$

where $\omega_{i}$ can be obtained by equations (A.10)-(A.13) according to drainage conditions. The detailed derivation for $\omega_{i}$ is shown in Appendix A.

Trapezoidal cyclic loading shown in Figure 2 can be expressed as follows:

$$
q(t)= \begin{cases}\frac{q_{u}}{\alpha t_{0}}\left[t-(N-1) \beta t_{0}\right], & (N-1) \beta t_{0} \leq t \leq[(N-1) \beta+\alpha] t_{0}, \\ q_{u}, & {[(N-1) \beta+\alpha] t_{0} \leq t \leq[(N-1) \beta+(1-\alpha)] t_{0},} \\ -\frac{q_{u}}{\alpha t_{0}}\left[t-(N-1) \beta t_{0}-t_{0}\right], & {[(N-1) \beta+(1-\alpha)] t_{0} \leq t \leq[(N-1) \beta+1] t_{0},} \\ 0, & {[(N-1) \beta+1] t_{0} \leq t \leq N \beta t_{0},}\end{cases}
$$

where $q_{u}$ is the maximum loading; $\beta t_{0}$ is the period of one loading cycle; $\alpha$ and $\beta$ are the loading parameters corresponding to the rate of loading increment or decrement and the rest period of loading, respectively; and $N$ is the cycle number.
By solving the integrals in equations (A.10)-(A.13) for the trapezoidal cyclic loading function, complete solutions for the excess pore water pressure of saturated doublelayered soil under trapezoidal cyclic loading can be expressed as follows:

$$
u_{i}=\left\{\begin{array}{ll}
\frac{q_{u} T_{1}}{N_{\sigma}-1}\left(1-e^{\omega_{i 1}}\right), \quad T_{v b 1} \leq T_{v 1} \leq T_{v b 1}+T_{v c 1}, \\
\frac{q_{u} N_{\sigma}}{N_{\sigma}-1}\left(1-e^{\omega_{i 2}}\right), & T_{v b 1}+T_{v c 1} \leq T_{v 1} \leq T_{v f 1}-T_{v c 1}, \\
\frac{q_{u} T_{2}}{N_{\sigma}-1}\left(1-e^{\omega_{i 3}}\right), & T_{v f 1}-T_{v c 1} \leq T_{v 1} \leq T_{v f 1}, \\
\frac{q_{u}}{N_{\sigma}-1}\left(1-e^{\omega_{i 4}}\right), & T_{v f 1} \leq T_{v 1} \leq T_{v N 1},
\end{array} \quad i=1,2,\right.
$$

where 


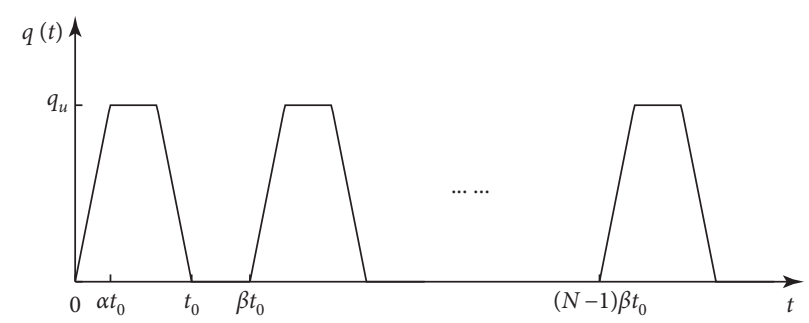

Figure 2: Trapezoidal cyclic loading.

$$
\begin{aligned}
T_{1} & =\frac{T_{v c 1}+\left(T_{v 1}-T_{v b 1}\right)\left(N_{\sigma}-1\right)}{T_{v c 1}}, T_{2}=\frac{T_{v c 1}+\left(T_{v f 1}-T_{v 1}\right)\left(N_{\sigma}-1\right)}{T_{v c 1}} \\
N_{\sigma} & =\frac{\sigma_{0}^{\prime}+q_{u}}{\sigma_{0}^{\prime}}, T_{v 1}=\frac{c_{v 1} t}{h_{1}^{2}}, T_{v c 1}=\frac{c_{v 1} \alpha t_{0}}{h_{1}^{2}}, \\
T_{v b 1} & =\frac{c_{v 1}(N-1) \beta t_{0}}{h_{1}^{2}}, T_{v f 1}=\frac{c_{v 1}[(N-1) \beta+1] t_{0}}{h_{1}^{2}}, T_{v N 1}=\frac{c_{v 1} N \beta t_{0}}{h_{1}^{2}} .
\end{aligned}
$$

For a single drainage condition,

$$
\begin{aligned}
& \omega_{1 j}=-\sum_{m=1}^{\infty} \sin \left(\lambda_{m} \frac{z}{h_{1}}\right) e^{-\lambda_{m}^{2} T_{v 1}} \frac{2 C_{j}}{\lambda_{m}\left(1+\mu^{2} \mathrm{KcA}_{m}^{2}\right)} \quad j=1,2,3,4, \\
& \omega_{2 j}=-\sum_{m=1}^{\infty} A_{m} \cos \left(\mu \lambda_{m} \frac{H-z}{h_{1}}\right) e^{-\lambda_{m}^{2} T_{v 1}} \frac{2 C_{j}}{\lambda_{m}\left(1+\mu^{2} \mathrm{KcA}_{m}^{2}\right)} \quad j=1,2,3,4 .
\end{aligned}
$$

For a double drainage condition,

$$
\begin{aligned}
& \omega_{1 j}=-\sum_{m=1}^{\infty} \sin \left(\lambda_{m} \frac{z}{h_{1}}\right) e^{-\lambda_{m}^{2} T_{v 1}} \frac{2\left(1+\mu \mathrm{KA}_{m}\right) C_{j}}{\lambda_{m}\left(1+\mu^{2} \mathrm{KcA}_{m}^{2}\right)} j=1,2,3,4, \\
& \omega_{2 j}=-\sum_{m=1}^{\infty} A_{m} \sin \left(\mu \lambda_{m} \frac{H-z}{h_{1}}\right) e^{-\lambda_{m}^{2} T_{v 1}} \frac{2\left(1+\mu \mathrm{KA}_{m}\right) C_{j}}{\lambda_{m}\left(1+\mu^{2} \mathrm{KcA}_{m}^{2}\right)} \quad j=1,2,3,4,
\end{aligned}
$$

where $A_{m}$ and $\lambda_{m}$ can be given by equations (A.2), (A.6), (A.14), and (A.15) according to drainage conditions. $c$ and $\mu$ The expressions of $C_{j}$ (i.e., $C_{1}, C_{2}, C_{3}$, and $C_{4}$ ) are as can be obtained by equations (A.3) and (A.5), respectively.

$$
\begin{aligned}
& C_{1}=D(N-1)+D_{1}, C_{2}=D(N-1)+D_{2}, C_{3}=D(N-1)+D_{2}+D_{3}, \\
& C_{4}=D(N), D(n)=\sum_{N=1}^{n}\left(D_{2}+D_{4}\right),
\end{aligned}
$$


where

$$
\begin{aligned}
& D_{1}=e^{\frac{\lambda_{m}^{2}\left[\left(N_{\sigma}-1\right) T_{v b 1}-T_{v c 1}\right]}{N_{\sigma}-1}}\left[\ln T_{1}+\sum_{k=1}^{\infty} \frac{\left(\lambda_{m}^{2} T_{v c 1}\right)^{k}\left(T_{1}^{k}-1\right)}{k ! k\left(N_{\sigma}-1\right)^{k}}\right], \\
& D_{2}=e^{\frac{\lambda_{m}^{2}\left[\left(N_{\sigma}-1\right) T_{v b 1}-T_{v c 1}\right]}{N_{\sigma}-1}}\left[\ln N_{\sigma}+\sum_{k=1}^{\infty} \frac{\left(\lambda_{m}^{2} T_{v c 1}\right)^{k}\left(N_{\sigma}^{k}-1\right)}{k ! k\left(N_{\sigma}-1\right)^{k}}\right] \text {, } \\
& D_{3}=e^{\frac{\lambda_{m}^{2}\left[\left(N_{\sigma}-1\right) T_{v f 1}+T_{v c 1}\right]}{N_{\sigma}-1}}\left[\ln \frac{T_{2}}{N_{\sigma}}+\sum_{k=1}^{\infty} \frac{\left(-\lambda_{m}^{2} T_{v c 1}\right)^{k}\left(T_{2}^{k}-N_{\sigma}^{k}\right)}{k ! k\left(N_{\sigma}-1\right)^{k}}\right] \text {, } \\
& D_{4}=e^{\frac{\lambda_{m}^{2}\left[\left(N_{\sigma}-1\right) T_{v f 1}+T_{v c 1}\right]}{N_{\sigma}-1}}\left[\ln \frac{1}{N_{\sigma}}+\sum_{k=1}^{\infty} \frac{\left(-\lambda_{m}^{2} T_{v c 1}\right)^{k}\left(1-N_{\sigma}^{k}\right)}{k ! k\left(N_{\sigma}-1\right)^{k}}\right] .
\end{aligned}
$$

3.1.2. Average Degree of Consolidation. The average degree of consolidation can be expressed either by settlement or by effective stress. The average degrees of consolidation for double-layered soil subjected to time-dependent loading can be written as follows [22]:

$$
\begin{aligned}
& U_{s}=\frac{U_{s 1}+\mu^{2} \mathrm{KcU}_{s 2}}{1+\mu^{2} \mathrm{Kc}}, \\
& U_{p}=\frac{U_{p 1}+c \mathrm{U}_{p 2}}{1+c},
\end{aligned}
$$

$$
\begin{aligned}
& U_{s 1}=\frac{\ln \left[\left(\sigma_{0}^{\prime}+q\right) / \sigma_{0}^{\prime}\right]+1 / h_{1} \int_{0}^{h_{1}} \omega_{1} \mathrm{~d} z}{\ln N_{\sigma}}, U_{s 2}=\frac{\ln \left[\left(\sigma_{0}^{\prime}+q\right) / \sigma_{0}^{\prime}\right]+1 / h_{2} \int_{h_{1}}^{H} \omega_{2} \mathrm{~d} z}{\ln N_{\sigma}}, \\
& U_{p 1}=\frac{q-1 / h_{1} \int_{0}^{h_{1}} u_{1} \mathrm{~d} z}{q_{u}}, U_{p 2}=\frac{q-1 / h_{2} \int_{h_{1}}^{H} u_{2} \mathrm{~d} z}{q_{u}} .
\end{aligned}
$$

For trapezoidal cyclic loading, complete solutions for the average degrees of consolidation can be written as follows: 


$$
\begin{aligned}
& \int \frac{1}{\ln N_{\sigma}}\left(\ln T_{1}-\frac{1}{1+\mu^{2} \mathrm{Kc}} \sum_{m=1}^{\infty} \frac{2 \mathrm{aC}_{1}}{\lambda_{m}^{2}\left(1+\mu^{2} \mathrm{KcA}_{m}^{2}\right)} e^{-\lambda_{m}^{2} T_{v 1}}\right), \quad T_{v b 1} \leq T_{v 1} \leq T_{v b 1}+T_{v c 1} \\
& \frac{1}{\ln N_{\sigma}}\left(\ln N_{\sigma}-\frac{1}{1+\mu^{2} \mathrm{Kc}} \sum_{m=1}^{\infty} \frac{2 \mathrm{aC}_{2}}{\lambda_{m}^{2}\left(1+\mu^{2} \mathrm{KcA}_{m}^{2}\right)} e^{-\lambda_{m}^{2} T_{v 1}}\right), \quad T_{v b 1}+T_{v c 1} \leq T_{v 1} \leq T_{v f 1}-T_{v c 1}, \\
& U_{s}=\{ \\
& \frac{1}{\ln N_{\sigma}}\left(\ln T_{2}-\frac{1}{1+\mu^{2} \mathrm{Kc}} \sum_{m=1}^{\infty} \frac{2 \mathrm{aC}_{3}}{\lambda_{m}^{2}\left(1+\mu^{2} \mathrm{KcA}_{m}^{2}\right)} e^{-\lambda_{m}^{2} T_{v 1}}\right), \quad T_{v f 1}-T_{v c 1} \leq T_{v 1} \leq T_{v f 1}, \\
& -\frac{1}{\ln N_{\sigma}\left(1+\mu^{2} \mathrm{Kc}\right)} \sum_{m=1}^{\infty} \frac{2 \mathrm{aC}_{4}}{\lambda_{m}^{2}\left(1+\mu^{2} \mathrm{KcA}_{m}^{2}\right)} e^{-\lambda_{m}^{2} T_{v 1},} \quad T_{v f 1} \leq T_{v 1} \leq T_{v N 1}, \\
& U_{p}= \begin{cases}\frac{T_{1}}{N_{\sigma}-1}\left[\frac{1}{H}\left(\int_{0}^{h_{1}} e^{\omega_{11}} \mathrm{~d} z+\int_{h_{1}}^{H} e^{\omega_{21}} \mathrm{~d} z\right)-\frac{1}{T_{1}}\right], & T_{v b 1} \leq T_{v 1} \leq T_{v b 1}+T_{v c 1}, \\
\frac{N_{\sigma}}{N_{\sigma}-1}\left[\frac{1}{H}\left(\int_{0}^{h_{1}} e^{\omega_{12}} \mathrm{~d} z+\int_{h_{1}}^{H} e^{\omega_{22}} \mathrm{~d} z\right)-\frac{1}{N_{\sigma}}\right], & T_{v b 1}+T_{v c 1} \leq T_{v 1} \leq T_{v f 1}-T_{v c 1}, \\
\frac{T_{2}}{N_{\sigma}-1}\left[\frac{1}{H}\left(\int_{0}^{h_{1}} e^{\omega_{13}} \mathrm{~d} z+\int_{h_{1}}^{H} e^{\omega_{23}} \mathrm{~d} z\right)-\frac{1}{T_{2}}\right], & T_{v f 1}-T_{v c 1} \leq T_{v 1} \leq T_{v f 1}, \\
\frac{1}{N_{\sigma}-1}\left[\frac{1}{H}\left(\int_{0}^{h_{1}} e^{\omega_{14}} \mathrm{~d} z+\int_{h_{1}}^{H} e^{\omega_{24}} d z\right)-1\right], & T_{v f 1} \leq T_{v 1} \leq T_{v N 1},\end{cases}
\end{aligned}
$$

where $a=1$ for a single drainage condition and $a=\left(1+\mu \mathrm{KA}_{m}\right)^{2}$ for a double drainage condition.

\subsection{Solutions for Rectangular and Triangular Cyclic Loadings.} Trapezoidal cyclic loading can be degenerated into rectangular cyclic loading and triangular cyclic loading. When $\alpha=0$, trapezoidal cyclic loading reduces into rectangular cyclic loading (Figure 3(a)). On the other hand, trapezoidal cyclic loading reduces to triangular cyclic loading (Figure 3(b)) when $\alpha=0.5$.

Analytical solutions for the excess pore water pressure under rectangular cyclic loading and triangular cyclic loading can be obtained substituting $\alpha=0$ and $\alpha=0.5$ into equation (12), respectively. Similarly, the average degrees of consolidation in terms of settlement and effective stress can also be given by equations (17) and (18).

\section{Degeneration to Special Cases}

The proposed solutions can be degenerated into existing solutions for 1D nonlinear consolidation of saturated double-layered soil under constant and ramp loadings and saturated single-layer soil under trapezoidal cyclic loading.
4.1. Solutions for Double-Layered Soil under Constant Loading. When $\alpha=0, \beta=1$, and $N=1$, trapezoidal cyclic loading reduces to constant loading (Figure 4(a)) expressed by $q(t)=q_{u}$. Then, the solution can be obtained as follows:

$$
\begin{aligned}
u_{i} & =\frac{q_{u} N_{\sigma}}{N_{\sigma}-1}\left(1-e^{\omega_{i}}\right), \quad i=1,2, \\
U_{s} & =1-\frac{1}{1+\mu^{2} \mathrm{Kc}} \sum_{m=1}^{\infty} \frac{2 a}{\lambda_{m}^{2}\left(1+\mu^{2} \mathrm{KcA}_{m}^{2}\right)} e^{-\lambda_{m}^{2} T_{v 1}}, \\
U_{p} & =\frac{N_{\sigma}}{N_{\sigma}-1}\left[\frac{1}{H}\left(\int_{0}^{h_{1}} e^{\omega_{1}} \mathrm{~d} z-\int_{h_{1}}^{H} e^{\omega_{2}} \mathrm{~d} z\right)-\frac{1}{N_{\sigma}}\right],
\end{aligned}
$$

where $\omega_{i}$ can be written as follows.

For a single drainage condition,

$$
\begin{aligned}
& \omega_{1}=-\ln N_{\sigma} \sum_{m=1}^{\infty} \sin \left(\lambda_{m} \frac{z}{h_{1}}\right) e^{-\lambda_{m}^{2} T_{v 1}} \frac{2}{\lambda_{m}\left(1+\mu^{2} \mathrm{KcA}_{m}^{2}\right)}, \\
& \omega_{2}=-\ln N_{\sigma} \sum_{m=1}^{\infty} A_{m} \cos \left(\mu \lambda_{m} \frac{H-z}{h_{1}}\right) e^{-\lambda_{m}^{2} T_{v 1}} \frac{2}{\lambda_{m}\left(1+\mu^{2} \mathrm{KcA}_{m}^{2}\right)} .
\end{aligned}
$$




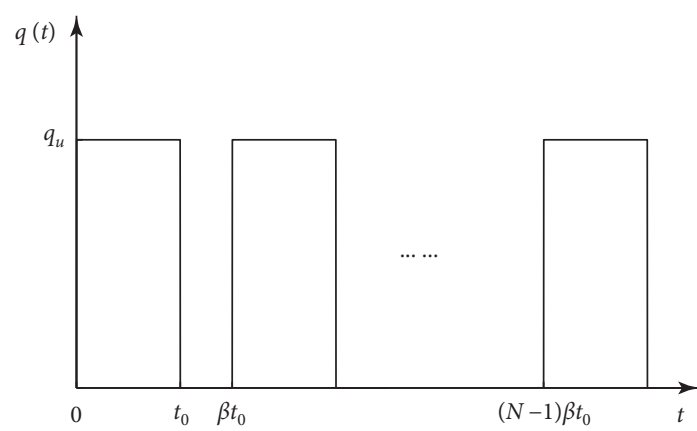

(a)

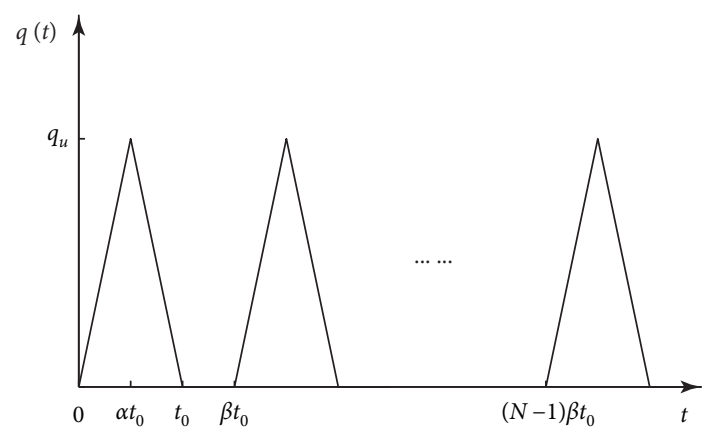

(b)

Figure 3: Rectangular cyclic loading (a) and triangular cyclic loading (b).

For a double drainage condition,

$$
\begin{aligned}
& \omega_{1}=-\ln N_{\sigma} \sum_{m=1}^{\infty} \sin \left(\lambda_{m} \frac{z}{h_{1}}\right) e^{-\lambda_{m}^{2} T_{v 1}} \frac{2\left(1+\mu \mathrm{KA}_{m}\right)}{\lambda_{m}\left(1+\mu^{2} \mathrm{KcA}_{m}^{2}\right)} \\
& \omega_{2}=-\ln N_{\sigma} \sum_{m=1}^{\infty} A_{m} \sin \left(\mu \lambda_{m} \frac{H-z}{h_{1}}\right) e^{-\lambda_{m}^{2} T_{v 1}} \frac{2\left(1+\mu \mathrm{KA}_{m}\right)}{\lambda_{m}\left(1+\mu^{2} \mathrm{KcA}_{m}^{2}\right)} .
\end{aligned}
$$

Equations (19)-(21) are the solutions for double-layered soil subjected to constant loading proposed by Xie et al. [22]

4.2. Solutions for Double-Layered Soil under Ramp Loading. When $N=1$ and $t_{0}$ tend to infinity, trapezoidal cyclic loading reduces to ramp loading (Figure 4(b)) given by

$$
q(t)= \begin{cases}\frac{t}{t_{c}} q_{u}, & t \leq t_{c}, \\ q_{w}, & t \geq t_{c},\end{cases}
$$

where $t_{c}=\alpha t_{0}$.

The solutions for double-layered soil under ramp loading can be obtained by

$$
\begin{aligned}
& u_{i}=\left\{\begin{array}{l}
\frac{q_{u} T}{N_{\sigma}-1}\left(1-e^{\omega_{i 1}}\right), \quad T_{v 1} \leq T_{v c 1}, \\
\frac{q_{u} N_{\sigma}}{N_{\sigma}-1}\left(1-e^{\omega_{i 2}}\right), \quad T_{v 1} \leq T_{v c 1}, \quad i=1,2,
\end{array}\right. \\
& U_{s}=\left\{\begin{array}{l}
\frac{1}{\ln N_{\sigma}}\left(\ln T-\frac{1}{1+\mu^{2} \mathrm{Kc}} \sum_{m=1}^{\infty} \frac{2 a C_{1}}{\lambda_{m}^{2}\left(1+\mu^{2} K c A_{m}^{2}\right)} e^{-\lambda_{m}^{2} T_{v 1}}\right), \quad T_{v 1} \leq T_{v c 1}, \\
\frac{1}{\ln N_{\sigma}}\left(\ln N_{\sigma}-\frac{1}{1+\mu^{2} \mathrm{Kc}} \sum_{m=1}^{\infty} \frac{2 a C_{2}}{\lambda_{m}^{2}\left(1+\mu^{2} K c A_{m}^{2}\right)} e^{-\lambda_{m}^{2} T_{v 1}}\right), \quad T_{v 1} \geq T_{v c 1},
\end{array}\right. \\
& U_{p}=\left\{\begin{array}{l}
\frac{T}{N_{\sigma}-1}\left[\frac{1}{H}\left(\int_{0}^{h_{1}} e^{\omega_{11}} d z-\int_{h_{1}}^{H} e^{\omega_{21}} \mathrm{~d} z\right)-\frac{1}{T}\right], \quad T_{v 1} \leq T_{v c 1}, \\
\frac{N_{\sigma}}{N_{\sigma}-1}\left[\frac{1}{H}\left(\int_{0}^{h_{1}} e^{\omega_{12}} d z-\int_{h_{1}}^{H} e^{\omega_{22}} \mathrm{~d} z\right)-\frac{1}{N_{\sigma}}\right], \quad T_{v 1} \geq T_{v c 1},
\end{array}\right.
\end{aligned}
$$




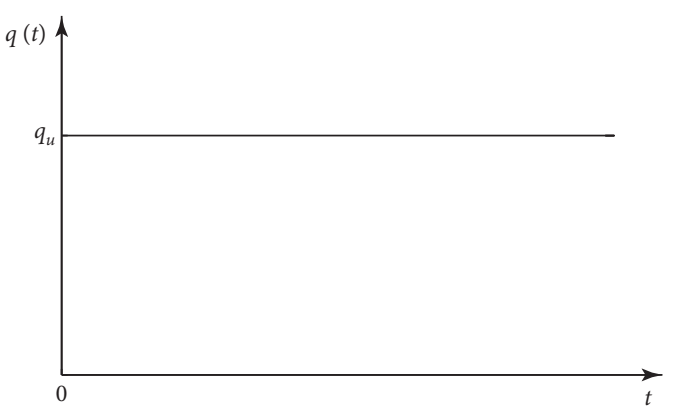

(a)

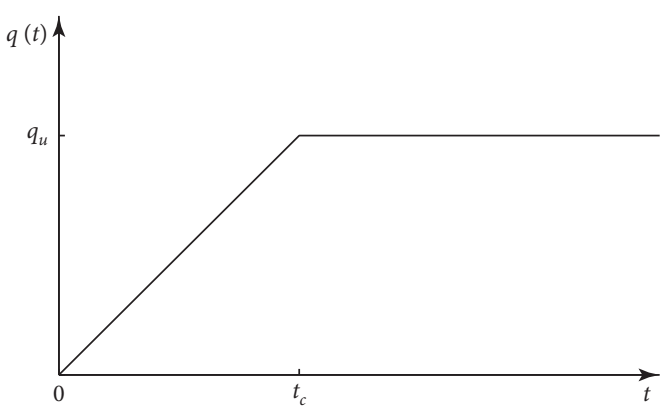

(b)

Figure 4: Constant loading (a) and ramp loading (b).

where $\omega_{i j}$ can be written as follows:

For a single drainage condition,

$$
\begin{aligned}
& \omega_{1 j}=-\sum_{m=1}^{\infty} \sin \left(\lambda_{m} \frac{z}{h_{1}}\right) e^{-\lambda_{m}^{2} T_{v 1}} \frac{2 C_{j}}{\lambda_{m}\left(1+\mu^{2} \mathrm{KcA}_{m}^{2}\right)}, \quad j=1,2, \\
& \omega_{2 j}=-\sum_{m=1}^{\infty} A_{m} \cos \left(\mu \lambda_{m} \frac{H-z}{h_{1}}\right) e^{-\lambda_{m}^{2} T_{v 1}} \frac{2 C_{j}}{\lambda_{m}\left(1+\mu^{2} \mathrm{KcA}_{m}^{2}\right)}, \quad j=1,2 .
\end{aligned}
$$

For a double drainage condition,

$$
\begin{aligned}
\omega_{1 j} & =-\sum_{m=1}^{\infty} \sin \left(\lambda_{m} \frac{z}{h_{1}}\right) e^{-\lambda_{m}^{2} T_{v 1}} \frac{2\left(1+\mu \mathrm{KA}_{m}\right) C_{j}}{\lambda_{m}\left(1+\mu^{2} \mathrm{KcA}_{m}^{2}\right)}, \quad j=1,2, \\
\omega_{2 j} & =-\sum_{m=1}^{\infty} A_{m} \sin \left(\mu \lambda_{m} \frac{H-z}{h_{1}}\right) e^{-\lambda_{m}^{2} T_{v 1}} \frac{2\left(1+\mu \mathrm{KA}_{m}\right) C_{j}}{\lambda_{m}\left(1+\mu^{2} \mathrm{KcA}_{m}^{2}\right)}, \quad j=1,2, \\
C_{1} & =e^{-\lambda_{m}^{2} T_{v c 1} 1\left(N_{\sigma}-1\right)}\left[\ln T+\sum_{k=1}^{\infty} \frac{\left(\lambda_{m}^{2} T_{v c 1}\right)^{k}\left(T^{k}-1\right)}{k ! k\left(N_{\sigma}-1\right)^{k}}\right], \\
C_{2} & =e^{-\lambda_{m}^{2} T_{v c 1} 1\left(N_{\sigma}-1\right)}\left[\ln N_{\sigma}+\sum_{k=1}^{\infty} \frac{\left(\lambda_{m}^{2} T_{v c 1}\right)^{k}\left(N_{\sigma}^{k}-1\right)}{k ! k\left(N_{\sigma}-1\right)^{k}}\right] \\
T & =\frac{T_{v c 1}+T_{v 1}\left(N_{\sigma}-1\right)}{T_{v c 1}}, \\
T_{v c 1} & =\frac{c_{v 1} t_{c}}{h_{1}^{2}}
\end{aligned}
$$

Equations (24)-(26) are the solutions for doublelayered soil under ramp loading proposed by Xie et al. [22].
4.3. Solutions for Single-Layer Soil under Trapezoidal Cyclic Loading. When $\mu=K=1$, the solutions for double-layered soil reduce to the solutions for single-layer soil. Therefore, 
the proposed solutions can be reduced to the solutions for 1D nonlinear consolidation of saturated single-layer soil subjected to trapezoidal cyclic loading as follows:

$$
\begin{aligned}
& u= \begin{cases}\frac{q_{u} T_{1}}{N_{\sigma}-1}\left(1-e^{-B_{1}}\right), & T_{v b} \leq T_{v} \leq T_{v b}+T_{v c}, \\
\frac{q_{u} N_{\sigma}}{N_{\sigma}-1}\left(1-e^{-B_{2}}\right), & T_{v b}+T_{v c} \leq T_{v} \leq T_{v f}-T_{v c}, \\
\frac{q_{u} T_{2}}{N_{\sigma}-1}\left(1-e^{-B_{3}}\right), & T_{v f}-T_{v c} \leq T_{v} \leq T_{v f}, \\
\frac{q_{u}}{N_{\sigma}-1}\left(1-e^{-B_{4}}\right), & T_{v f} \leq T_{v} \leq T_{v N},\end{cases} \\
& \int \frac{1}{\ln N_{\sigma}}\left(\ln T_{1}-\sum_{m=1}^{\infty} \frac{2 E_{1}}{M^{2}} e^{-M^{2} T_{v}}\right), \quad T_{v b} \leq T_{v} \leq T_{v b}+T_{v c}, \\
& U_{s}= \begin{cases}\frac{1}{\ln N_{\sigma}}\left(\ln N_{\sigma}-\sum_{m=1}^{\infty} \frac{2 E_{2}}{M^{2}} e^{-M^{2} T_{v}}\right), & T_{v b}+T_{v c} \leq T_{v} \leq T_{v f}-T_{v c}, \\
\frac{1}{\ln N_{\sigma}}\left(\ln T_{2}-\sum_{m=1}^{\infty} \frac{2 E_{3}}{M^{2}} e^{-M^{2} T_{v}}\right), & T_{v f}-T_{v c} \leq T_{v} \leq T_{v f},\end{cases} \\
& -\frac{1}{\ln N_{\sigma}} \sum_{m=1}^{\infty} \frac{2 E_{4}}{M^{2}} e^{-M^{2} T_{v}}, \quad T_{v f} \leq T_{v} \leq T_{v N} \text {, } \\
& U_{p}= \begin{cases}\frac{T_{1}}{N_{\sigma}-1}\left(\frac{1}{H} \int_{0}^{H} e^{-B_{1}} \mathrm{~d} z-\frac{1}{T_{1}}\right), & T_{v b} \leq T_{v} \leq T_{v b}+T_{v c}, \\
\frac{N_{\sigma}}{N_{\sigma}-1}\left(\frac{1}{H} \int_{0}^{H} e^{-B_{2}} \mathrm{~d} z-\frac{1}{N_{\sigma}}\right), & T_{v b}+T_{v c} \leq T_{v} \leq T_{v f}-T_{v c}, \\
\frac{T_{2}}{N_{\sigma}-1}\left(\frac{1}{H} \int_{0}^{H} e^{-B_{3}} \mathrm{~d} z-\frac{1}{T_{2}}\right), & T_{v f}-T_{v c} \leq T_{v} \leq T_{v f}, \\
\frac{1}{N_{\sigma}-1}\left(\frac{1}{H} \int_{0}^{H} e^{-B_{4}} \mathrm{~d} z-1\right), & T_{v f} \leq T_{v} \leq T_{v N},\end{cases}
\end{aligned}
$$

where

$$
\begin{aligned}
T_{1} & =\frac{T_{v c}+\left(T_{v}-T_{v b}\right)\left(N_{\sigma}-1\right)}{T_{v c}}, T_{2}=\frac{T_{v c}+\left(T_{v f}-T_{v}\right)\left(N_{\sigma}-1\right)}{T_{v c}}, \\
N_{\sigma} & =\frac{\sigma_{0}^{\prime}+q_{u}}{\sigma_{0}^{\prime}}, T_{v}=\frac{c_{v} t}{h^{2}}, T_{v c}=\frac{c_{v} \alpha t_{0}}{h^{2}}, M=\frac{(2 m-1) \pi}{2}, \\
T_{v b} & =\frac{c_{v}(N-1) \beta t_{0}}{h^{2}}, T_{v f}=\frac{c_{v}[(N-1) \beta+1] t_{0}}{h^{2}}, T_{v N}=\frac{c_{v} N \beta t_{0}}{h^{2}}, \\
B_{j} & =\sum_{m=1}^{\infty} \frac{2 E_{j}}{M} \sin \left(\frac{\mathrm{Mz}}{h}\right) e^{-M^{2} T_{v}}, j=1,2,3,4,
\end{aligned}
$$




$$
\begin{aligned}
& E_{1}=F(N-1)+F_{1}, E_{2}=F(N-1)+F_{2}, E_{3}=F(N-1)+F_{2}+F_{3}, \\
& E_{4}=F(N), F(n)=\sum_{N=1}^{n}\left(F_{2}+F_{4}\right), \\
& F_{1}=e^{M^{2}\left[T_{v b}\left(N_{\sigma}-1\right)-T_{v c}\right] /\left(N_{\sigma}-1\right)}\left[\ln T_{1}+\sum_{k=1}^{\infty} \frac{\left(M^{2} T_{v c}\right)^{k}\left(T_{1}^{k}-1\right)}{\left.k ! k\left(N_{\sigma}-1\right)^{k}\right],}\right. \\
& F_{2}=e^{M^{2}\left[T_{v b}\left(N_{\sigma}-1\right)-T_{v c}\right] /\left(N_{\sigma}-1\right)}\left[\ln N_{\sigma}+\sum_{k=1}^{\infty} \frac{\left(M^{2} T_{v c}\right)^{k}\left(N_{\sigma}^{k}-1\right)}{\left.k ! k\left(N_{\sigma}-1\right)^{k}\right],}\right. \\
& F_{3}=e^{M^{2}\left[T_{v f}\left(N_{\sigma}-1\right)+T_{v c}\right] /\left(N_{\sigma}-1\right)}\left[\ln \frac{T_{2}}{N_{\sigma}}+\sum_{k=1}^{\infty} \frac{\left(-M^{2} T_{v c}\right)^{k}\left(T_{2}^{k}-N_{\sigma}^{k}\right)}{k ! k\left(N_{\sigma}-1\right)^{k}}\right], \\
& F_{4}=e^{M^{2}\left[T_{v f}\left(N_{\sigma}-1\right)+T_{v c}\right] /\left(N_{\sigma}-1\right)}\left[\ln \frac{1}{N_{\sigma}}+\sum_{k=1}^{\infty} \frac{\left(-M^{2} T_{v c}\right)^{k}\left(1-N_{\sigma}^{k}\right)}{\left.k ! k\left(N_{\sigma}-1\right)^{k}\right] .}\right.
\end{aligned}
$$

$h=H$ (for single drainage condition) and $h=H / 2$ (for a double drainage condition).

Equations (28)-(30) are the solutions for 1D nonlinear consolidation of single-layer soil under trapezoidal cyclic loading presented by Xie et al. [10].

Figure 5 shows the comparison between the degenerate solutions and the existing solutions for double-layered soil subjected to constant loading (Figures 5(a) and 5(b)) and ramp loading (Figure 5(c)) and single-layer soil subjected to trapezoidal cyclic loading (Figure 5(d)). It can be found that the degenerate solutions from this paper show good agreement with the existing results, which proves that the proposed solutions are more general ones for 1D nonlinear consolidation of saturated soils under time-dependent loading.

\section{Parametric Study}

In this section, a comprehensive parametric study is conducted to investigate the influences of different layer parameters, drainage conditions, and loading parameters on nonlinear consolidation behavior of saturated double-layered soil under various cyclic loadings.

5.1. Influence of Layer Parameters. In order to investigate the influences of layer parameters such as the permeability ratio $K$ (i.e., $K=k_{v}^{2} / k_{v}^{1}$ ), the compressibility ratio $b$ (i.e. $b=m_{v}^{2} / m_{v}^{1}$ ), and the thickness ratio $c$ (i.e., $\left.c=h_{2} / h_{1}\right)$, the saturated double-layered soil of total thickness $H=10 \mathrm{~m}$ with single drainage condition under various cyclic loadings is considered. The cyclic loadings are trapezoidal $(\alpha=0.2)$ and rectangular and triangular cyclic loadings with $\beta=1.5, T_{0}=0.04$, and $N_{\sigma}=2.5$, where $T_{0}$ is time factor defined by $T_{0}=c_{v 1} t_{0} / H^{2}$.

5.1.1. The Permeability Ratio $K$. For the effect of $K$, it is assumed that $b=1$ and $c=1$. Figure 6 presents the excess pore pressure isochrones at the end of loading and unloading stages of the 10th cycle for trapezoidal cyclic loading. Cyclic loadings include loading stage and unloading stage in each cycle unlike static loading, which results in squeezing out of pore water during loading stage and then absorbing during unloading stage. Thus, the excess pore pressures have both positive values for the loading stage and negative values for the unloading stage as shown in Figure 6. It can be shown that the excess pore pressure is smaller for the bigger value of $K$ in the lower layer, while $K$ has no significant effects in the upper layer. It implies that the bigger permeability of the lower layer leads to the faster dissipation rate of pore pressure when the compressibilities of the two layers are the same.

Figure 7 shows the variations of average degrees of consolidation in terms of settlement and effective stress with time factor $T_{v}$ under different values of $K$ for trapezoidal cyclic loading (Figure $7(\mathrm{a})$ ), rectangular cyclic loading (Figure 7(b)), and triangular cyclic loading (Figure 7(c)). The time factor $T_{v}$ is defined by $T_{v}=c_{v 1} t / H^{2}$. It can be seen that there are almost no differences in $U_{s}$ and $U_{p}$ between different values of $K$ at the early stages of consolidation, but the greater $K$ increases the rates of settlement and dissipation of excess pore pressure with fluctuation as time grows. Moreover, the effects are obvious for the case of $K<1$ but not clear for the opposite case. It can be explained that the effects of $K$ is mainly related to the permeability of the lower layer, indicating that for a single drainage condition, the smaller permeability of the lower layer decreases the rates of settlement and dissipation of excess pore pressure.

5.1.2. The Compressibility Ratio $b$. The effect of the compressibility ratio $b$ is investigated for double-layered soil with $K=1$ and $c=1$. Figure 8 illustrates the excess pore pressure isochrones at the end of loading and unloading stages of the 10th cycle for trapezoidal cyclic loading. It can be found that when the permeabilities of the two layers are the same, the greater the compressibility ratio $b$ is, the greater the excess 


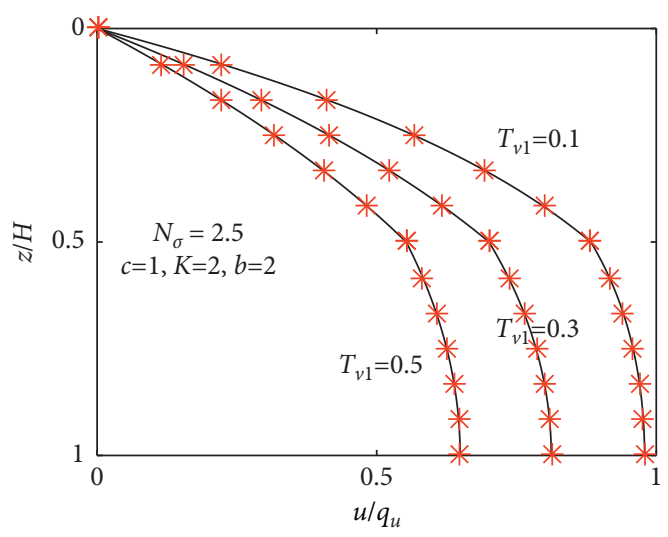

* Xie et al. [22]

(a)

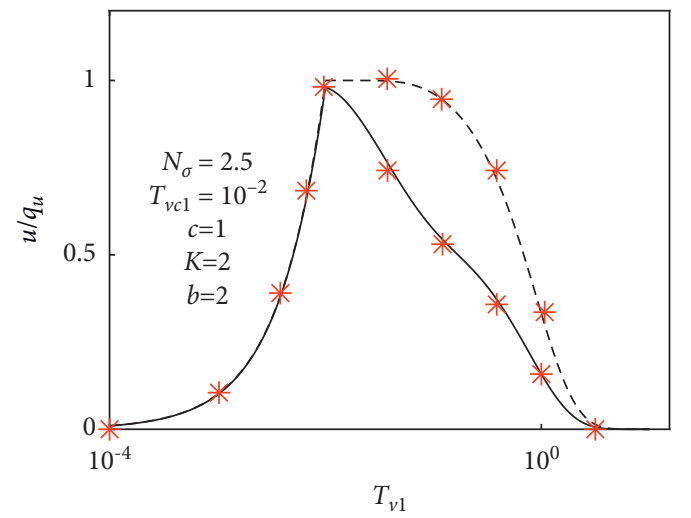

$\begin{array}{ll}- & z / H=1 / 4 \\ --- & z / H=3 / 4 \\ * \quad \text { Xie et al. [22] }\end{array}$

(c)

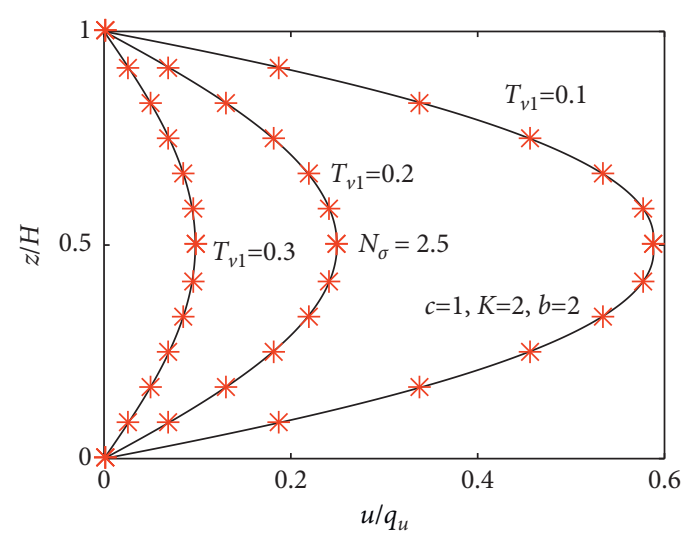

* Xie et al. [22]

(b)

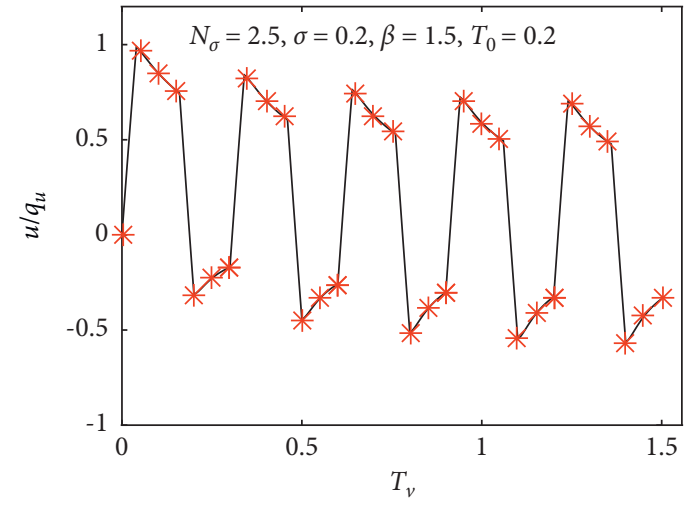

* Xie et al. [10]

(d)

Figure 5: Comparison between the degenerate solutions and the existing solutions.
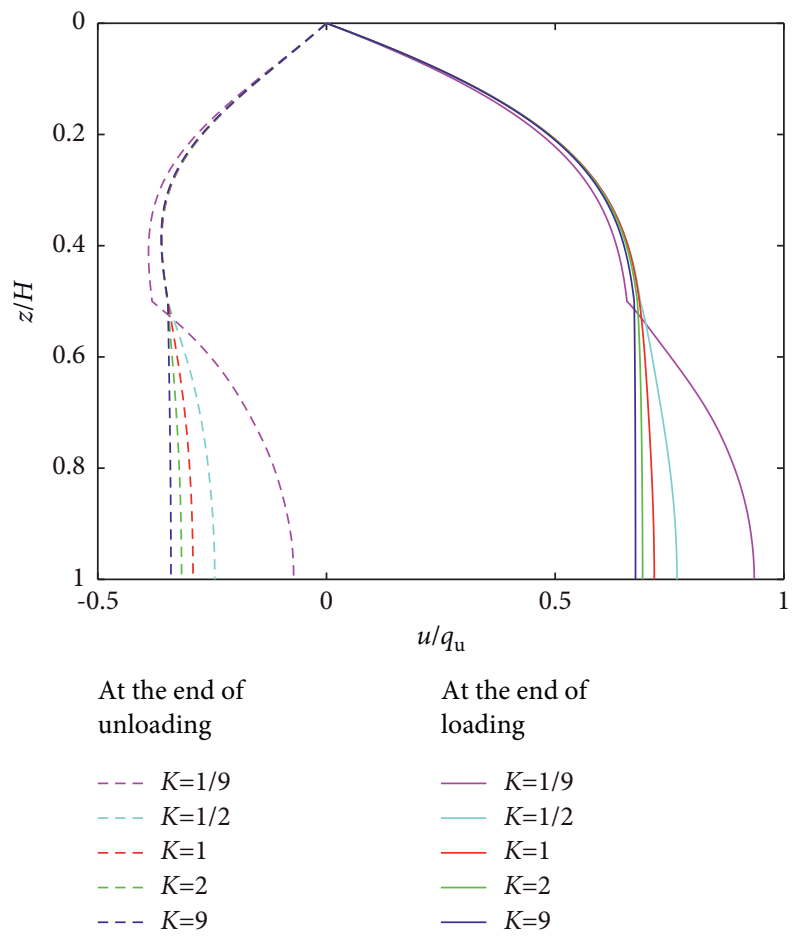

Figure 6: The excess pore pressure isochrones under different values of $K$. 

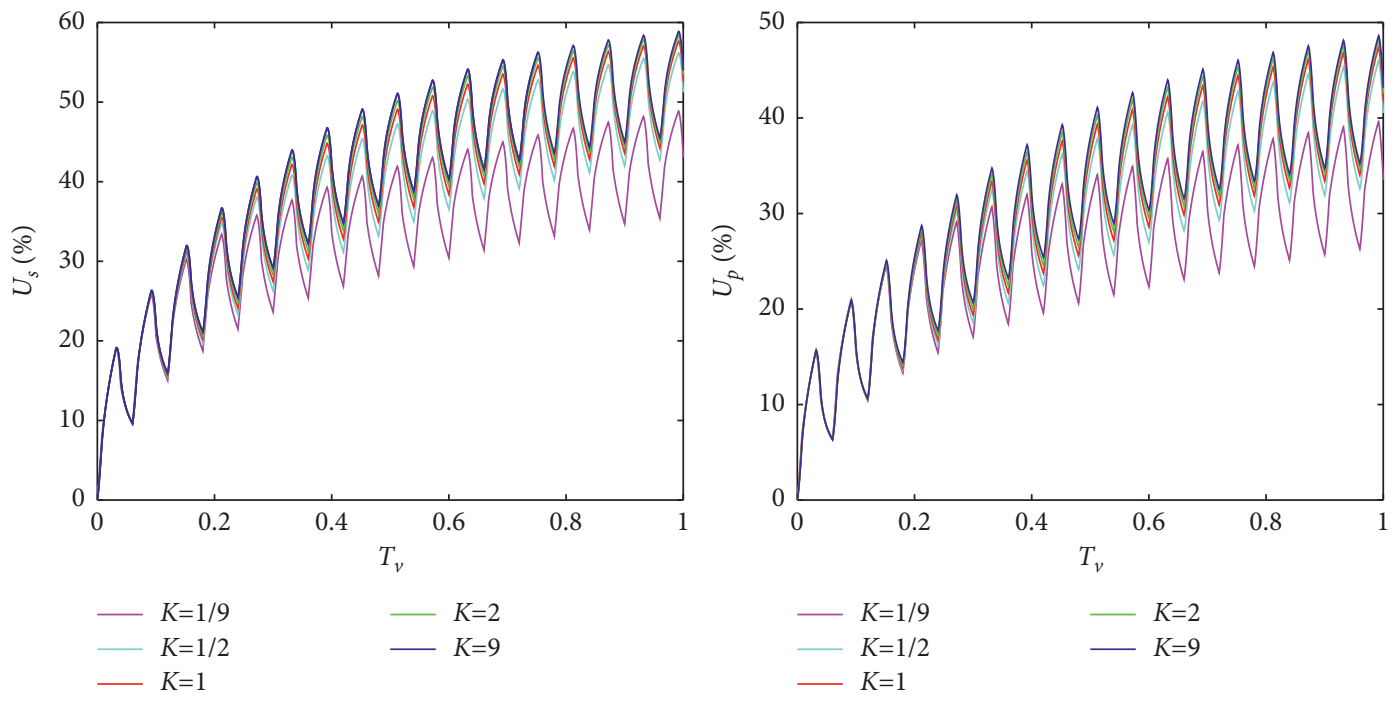

(a)
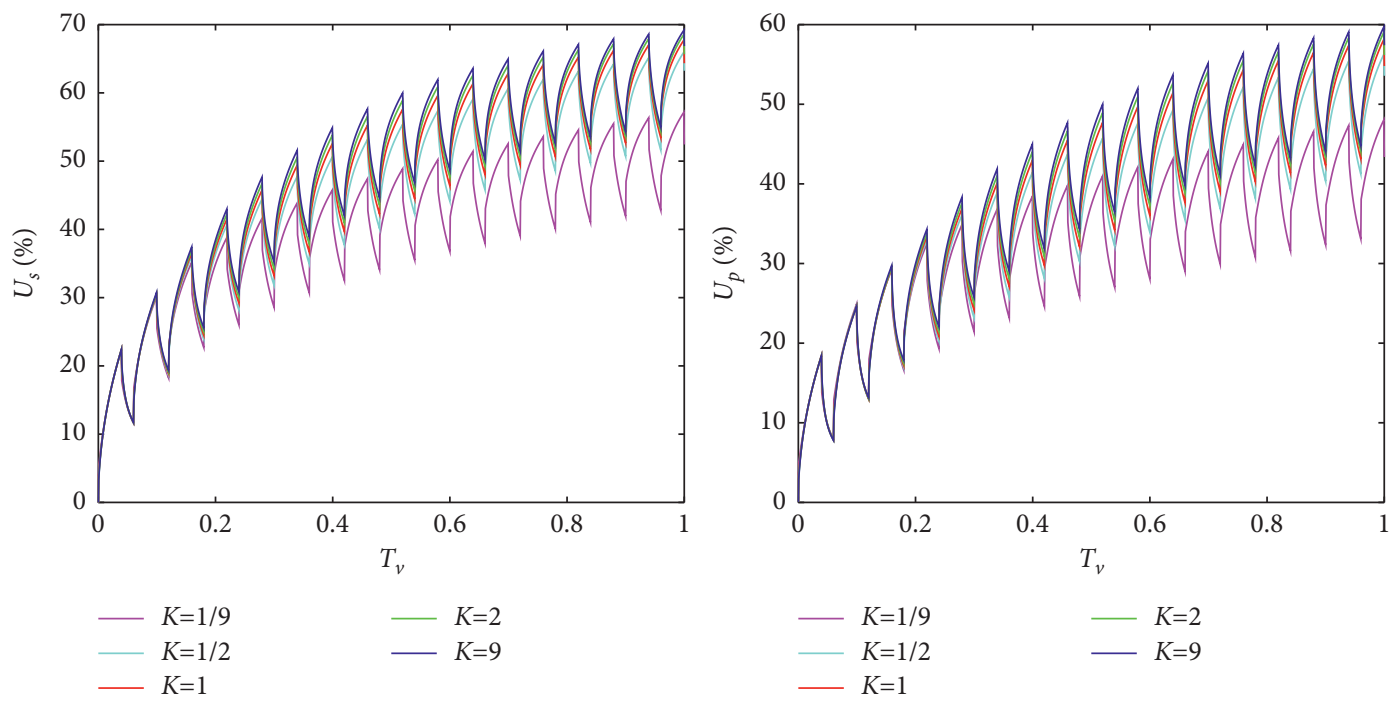

(b)
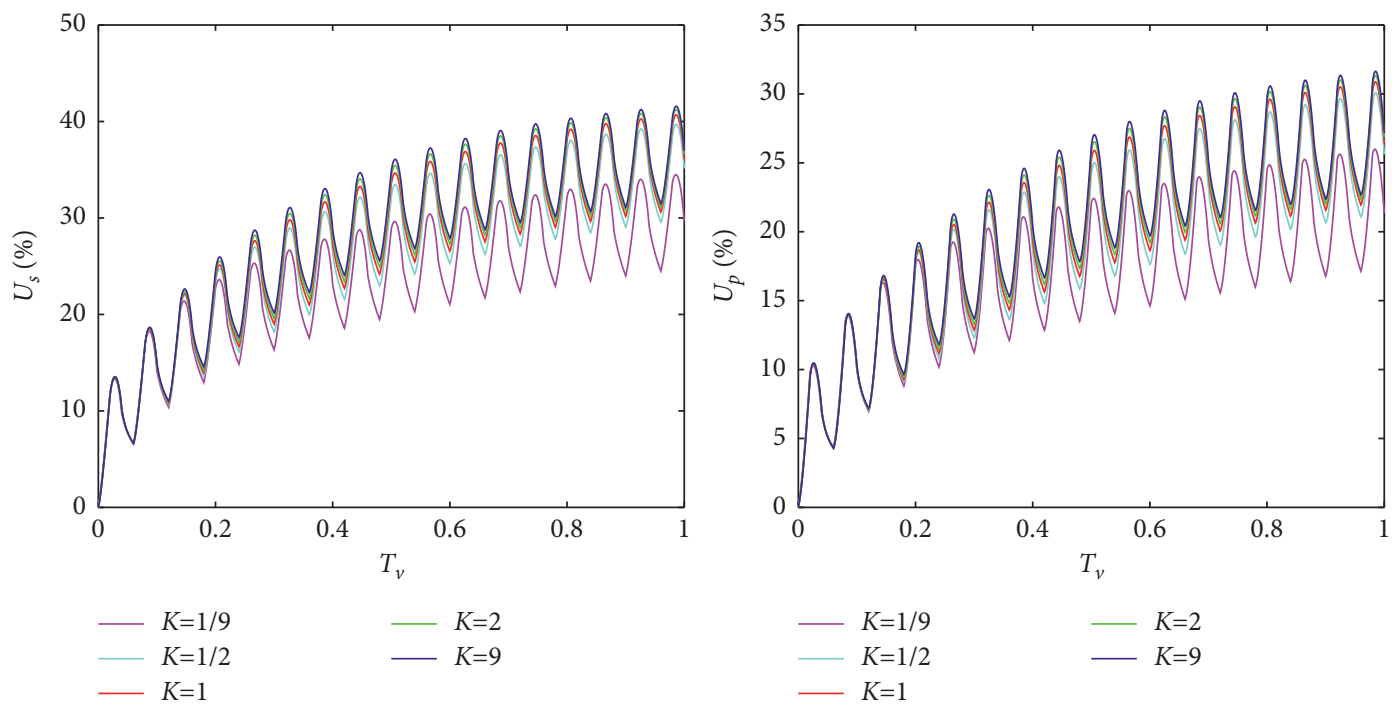

(c)

FIgURE 7: The variations of average degrees of consolidation $U_{s}$ and $U_{p}$ with time factor $T_{v}$ under different values of $K$. 


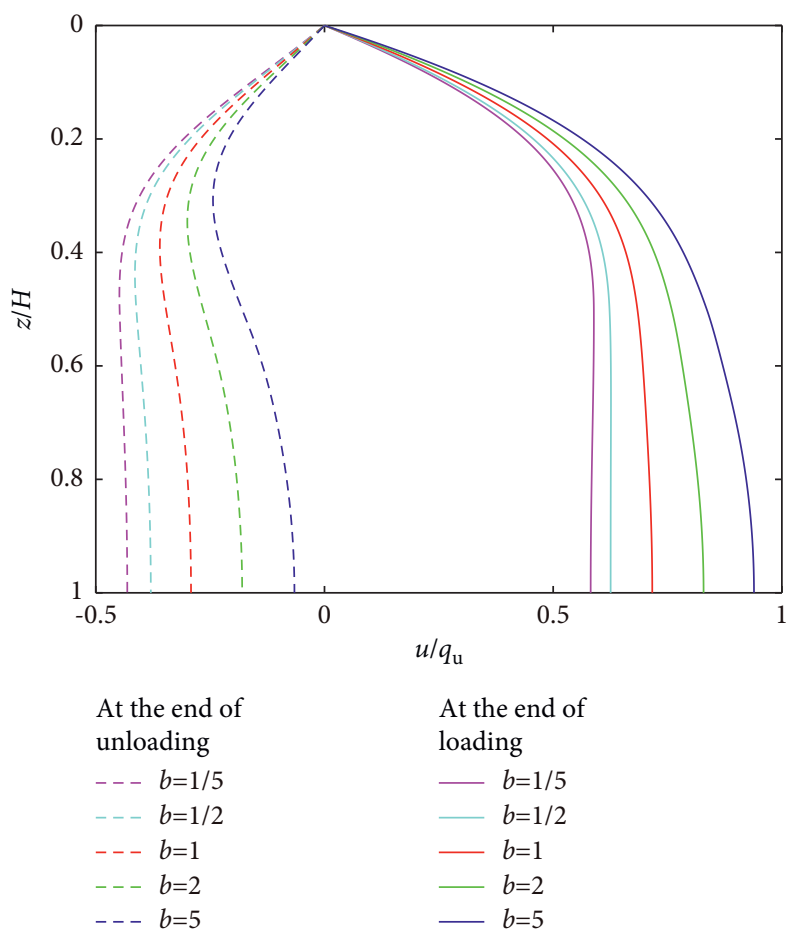

Figure 8: The excess pore pressure isochrones under different values of $b$.

pore pressure is, indicating that an increase in the compressibility of the lower layer will decrease the rate of consolidation.

The effect of the compressibility ratio $b$ can also be found in Figure 9. Figure 9 represents the variations of average degree of consolidation in terms of effective stress $U_{p}$ with time factor $T_{v}$ under different values of $b$ for three different cyclic loadings, such as trapezoidal cyclic loading (Figure 9(a)), rectangular cyclic loading (Figure 9(b)), and triangular cyclic loading (Figure $9(\mathrm{c})$ ). Similar to the abovementioned result, it can be seen that the increase in the compressibility ratio $b$ decreases the dissipation rate of excess pore pressure with fluctuation when the permeabilities of the two layers are the same.

5.1.3. The Thickness Ratio $c$. The effect of the thickness ratio $c$ is studied for two cases of double-layered soil: Case 1 is for $K=2$ and $b=1$ and Case 2 is for $K=1$ and $b=2$. Figure 10 depicts the excess pore pressure isochrones at the end of loading and unloading stages of the 10th cycle for trapezoidal cyclic loading. It can be found that excess pore pressure decreases when the thickness ratio $c$ increases for Case 1, but the opposite occurs for Case 2. It implies that in the lower layer with higher permeability, the greater thickness results in the smaller excess pore pressure, whereas the increase in thickness of the lower layer with higher compressibility leads to the bigger excess pore pressure.

Figure 11 demonstrates the variations of average degree of consolidation in terms of settlement $U_{s}$ with time factor $T_{v}$ under different values of the thickness ratio $c$ for trapezoidal cyclic loading (Figures 11(a) and 11(b)), rectangular cyclic loading (Figures 11(c) and 11(d)), and triangular cyclic loading (Figures 11(e) and 11(f)). It can be seen that the effect of the thickness ratio $c$ is similar to the above described in Figure 10. For Case 1, the rate of settlement increases a little with fluctuation when the thickness ratio $c$ increases. As for Case 2, the effect of the thickness ratio $c$ is opposite. In addition, the rate of settlement increases obviously when the thickness of the lower layer with higher compressibility decreases.

5.2. Influence of Drainage Conditions. The influence of drainage conditions is investigated for double-layered soil with $K=2, b=1$, and $c=1$. Figure 12 shows the variations of average degrees of consolidation in terms of settlement and effective stress with time factor $T_{v}$ under different drainage conditions for trapezoidal cyclic loading (Figure 12(a)), rectangular cyclic loading (Figure 12(b)), and triangular cyclic loading (Figure 12(c)). It can be found that the rates of settlement and dissipation of excess pore pressure for a double drainage condition are bigger than those for a single drainage condition. Moreover, the amplitudes of fluctuation in the rates of settlement and dissipation of excess pore pressure under a double drainage condition are also greater than those under a single drainage condition.

5.3. Influence of Loading Parameters. The influence of loading parameters such as $\alpha, \beta$, and $T_{0}$ is analysed for double-layered soil with $K=2, b=2$, and $c=1$.

5.3.1. The Loading Parameter $\alpha$. Figure 13 presents the variations of average degrees of consolidation $U_{s}$ and $U_{p}$ with time factor $T_{v}$ under cyclic loadings with different values of 


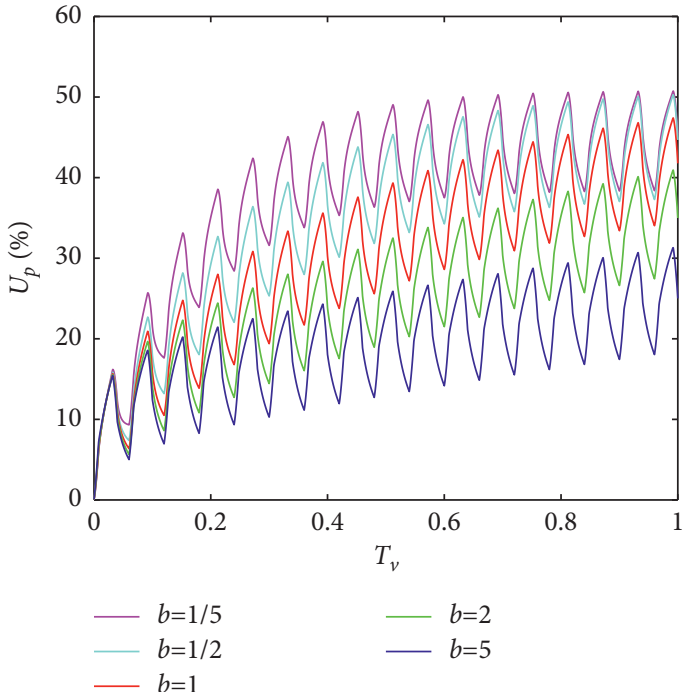

(a)

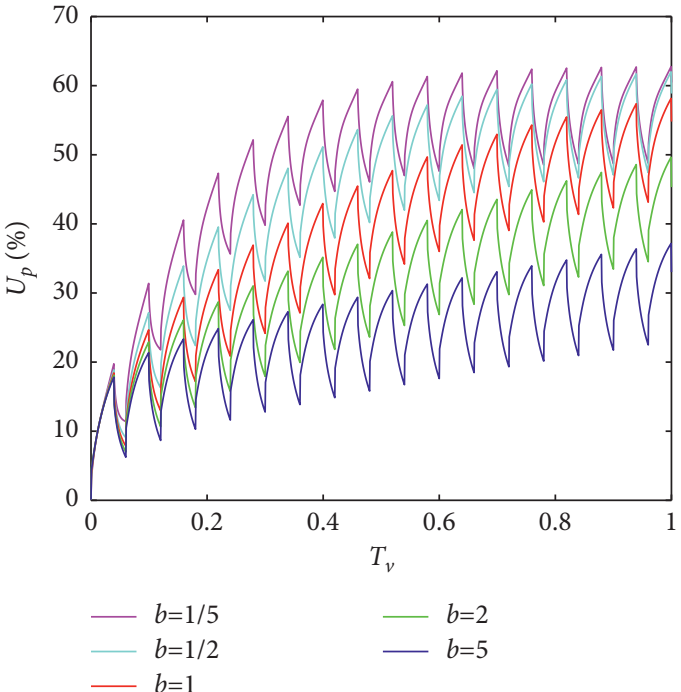

(b)

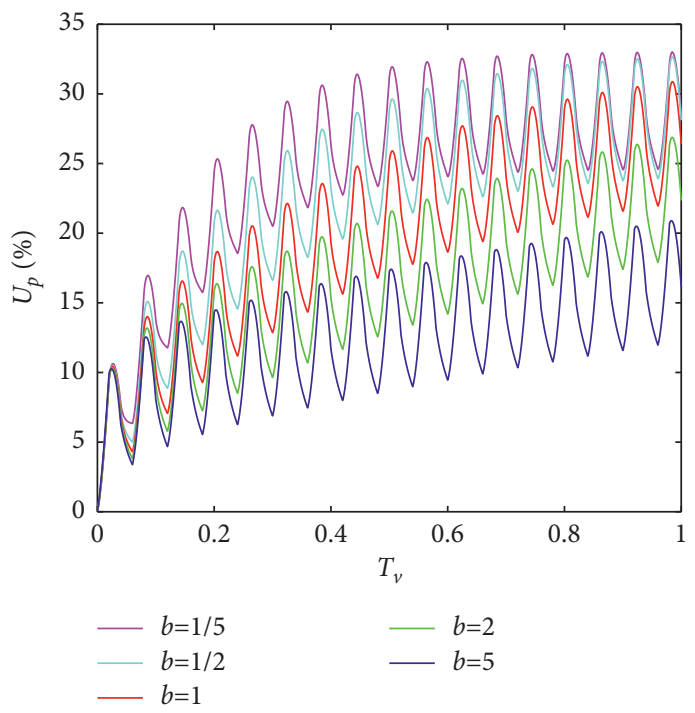

(c)

Figure 9: The variations of average degree of consolidation $U_{p}$ with time factor $T_{v}$ under different values of $b$.

$\alpha$. It can be seen that both the settlement rate and the dissipation rate of excess pore pressure decrease with the increase of the value of $\alpha$. The loading parameter $\alpha$ reflects the rate of increment or decrement of loading, and thus, it can be concluded that the greater the rate of increment or decrement of loading, the greater the rate of consolidation. In this context, the rate of consolidation for rectangular cyclic loading is the biggest and the rate of consolidation for triangular cyclic loading is the smallest.

5.3.2. The Loading Parameter $\beta$. Figure 14 depicts the variations of average degrees of consolidation $U_{s}$ and $U_{p}$ with time factor $T_{v}$ under trapezoidal cyclic loading (Figure 14(a)), rectangular cyclic loading (Figure 14(b)), and triangular cyclic loading (Figure 14(c)) with different values of $\beta$. It can be found that the increase of the value of $\beta$ results in the smaller rates of settlement and dissipation of excess pore pressure and less cycles and bigger amplitude of fluctuation in the rates of settlement and dissipation of excess pore pressure. The loading parameter $\beta$ reflects the rest period of cyclic loadings. Therefore, it can be concluded that the rate of consolidation under cyclic loadings increases with the decrease of the rest period of cyclic loading. As a result, the rate of consolidation under cyclic loadings without rest period (i.e., $\beta=1$ ) is the biggest; especially, the rectangular cyclic loading without rest period reduces the constant loading, and the rate of consolidation under constant loading is the highest.

5.3.3. The Loading Parameter $T_{0}$. Figure 15 represents the variations of average degrees of consolidation $U_{s}$ and $U_{p}$ with time factor $T_{v}$ under trapezoidal cyclic loading 


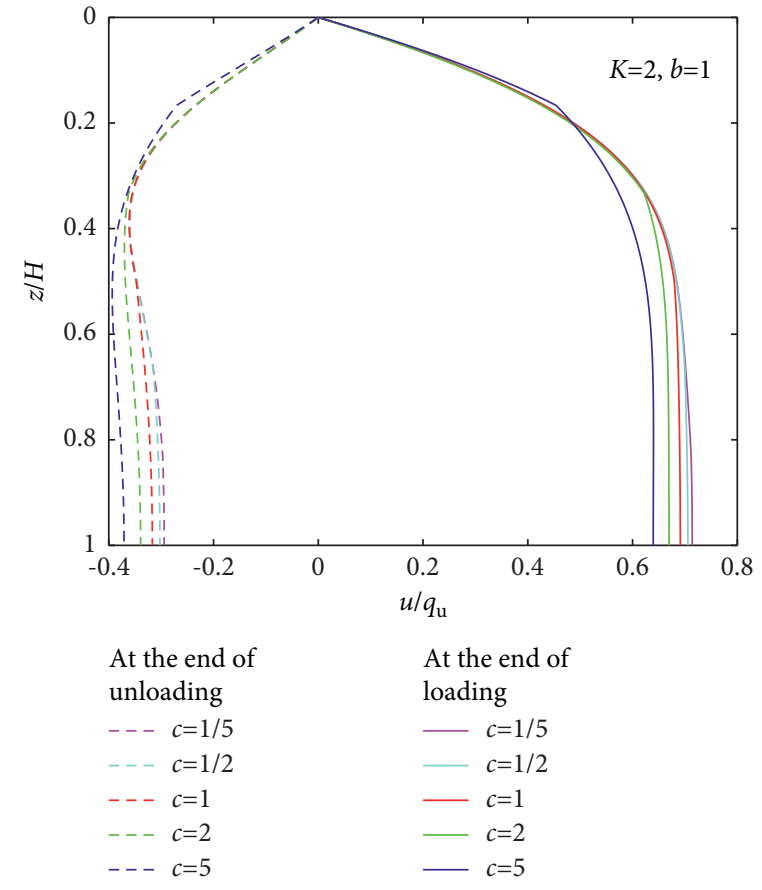

(a)

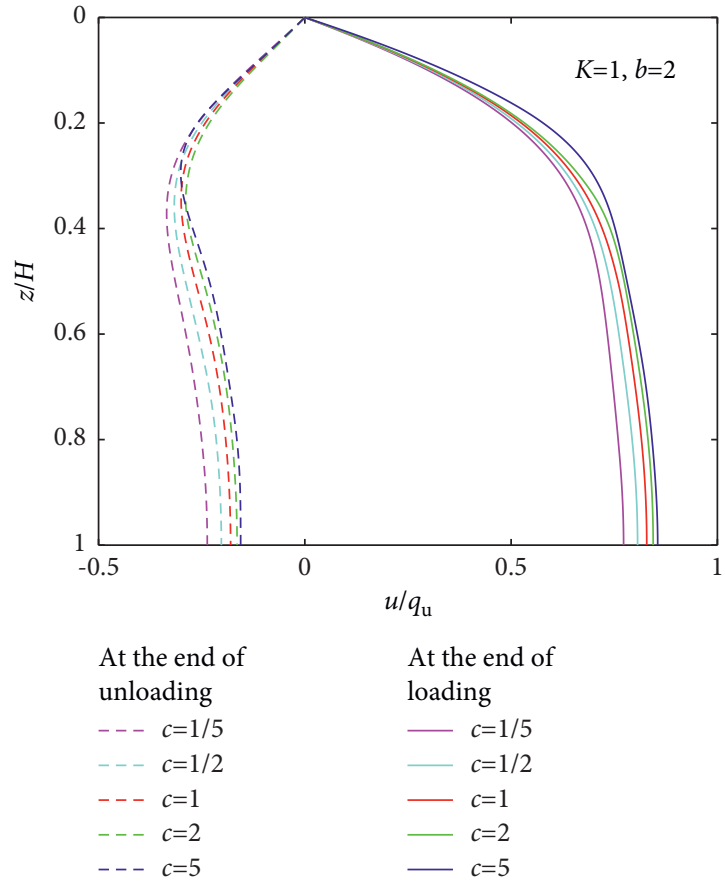

(b)

FIgURE 10: The excess pore pressure isochrones under different values of $c$.

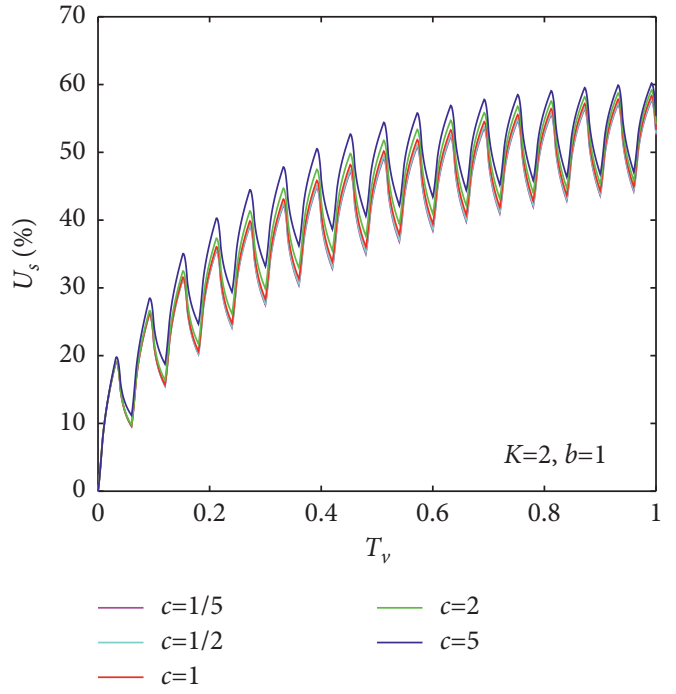

(a)

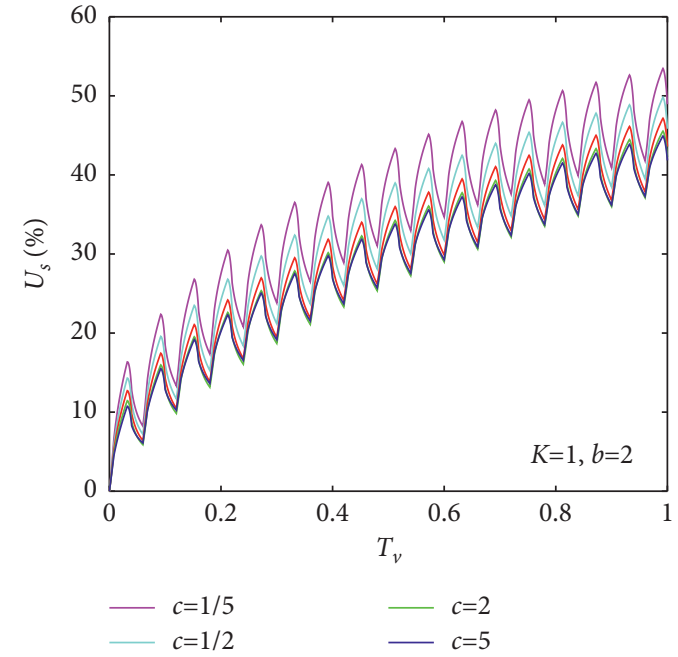

(b)

Figure 11: Continued. 


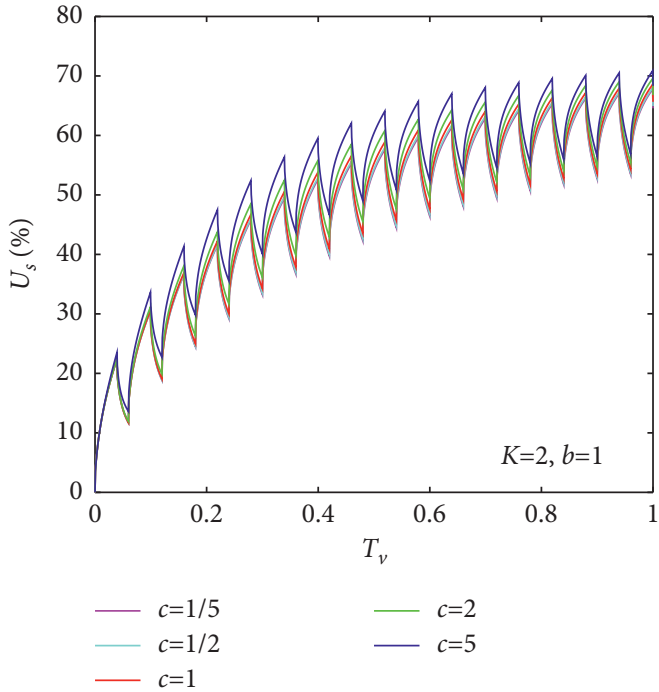

(c)

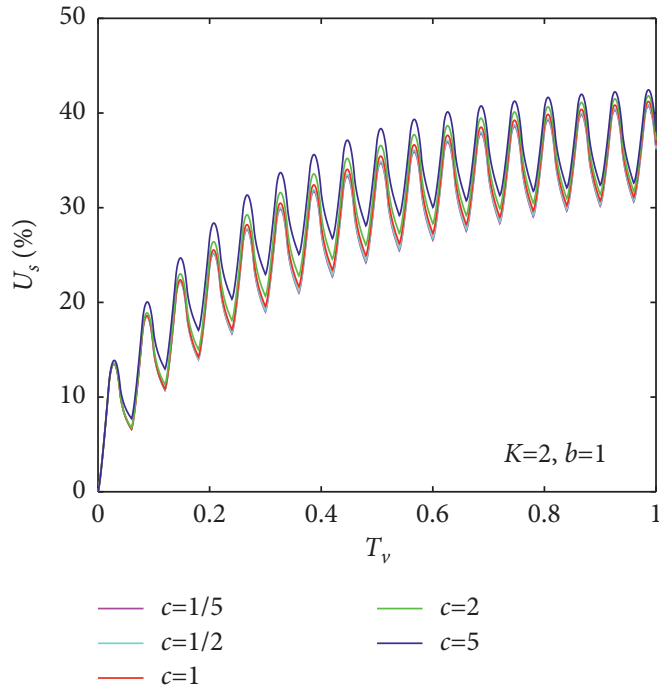

(e)

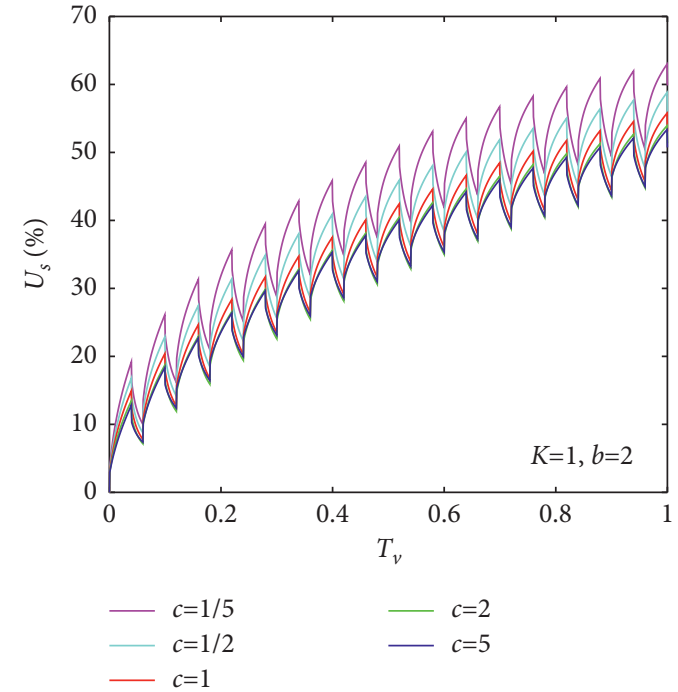

(d)

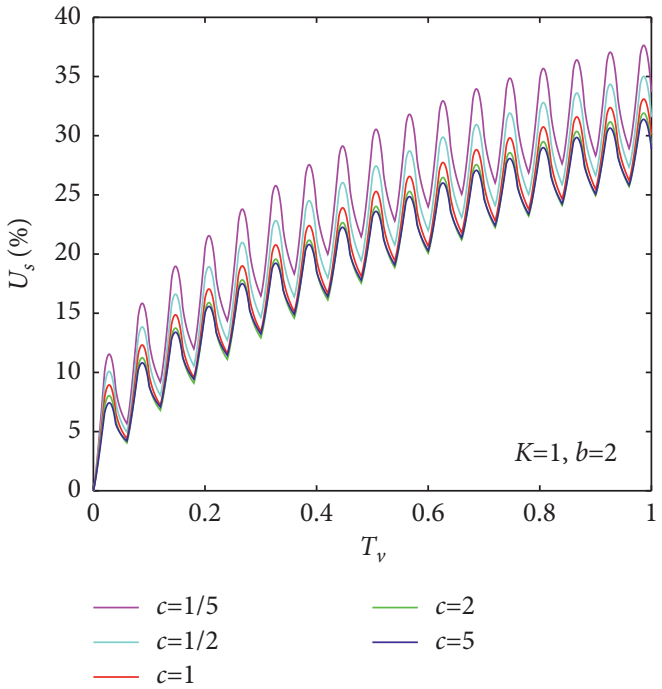

(f)

FIgURE 11: The variations of average degree of consolidation $U_{s}$ with time factor $T_{v}$ under different values of $c$.

(Figure 15(a)), rectangular cyclic loading (Figure 15(b)), and triangular cyclic loading (Figure 15(c)) with different values of $T_{0}$. It can be seen that a smaller value of $T_{0}$ induces more cycles and smaller amplitude of fluctuation in the rates of settlement and dissipation of excess pore pressure, but the loading parameter $T_{0}$ has no effects on the average values of the rates of settlement and dissipation of excess pore pressure. Since the loading parameter $T_{0}$ reflects the period of loading, it can be found that the longer the period of loading, the bigger amplitude and less cycles of fluctuation in the settlement rate and the dissipation rate of excess pore pressure. 


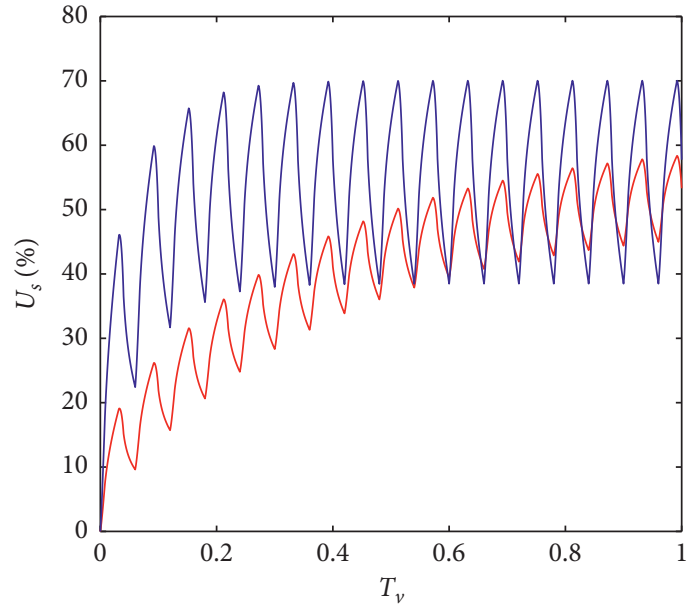

Single drainage
$\ldots$ Double drainage
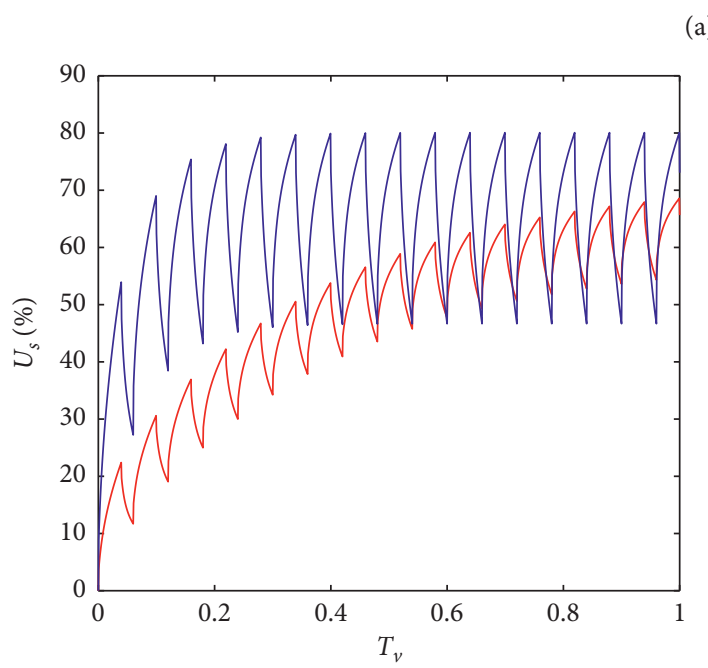

Single drainage
_ Double drainage



_ Single drainage
_ Double drainage

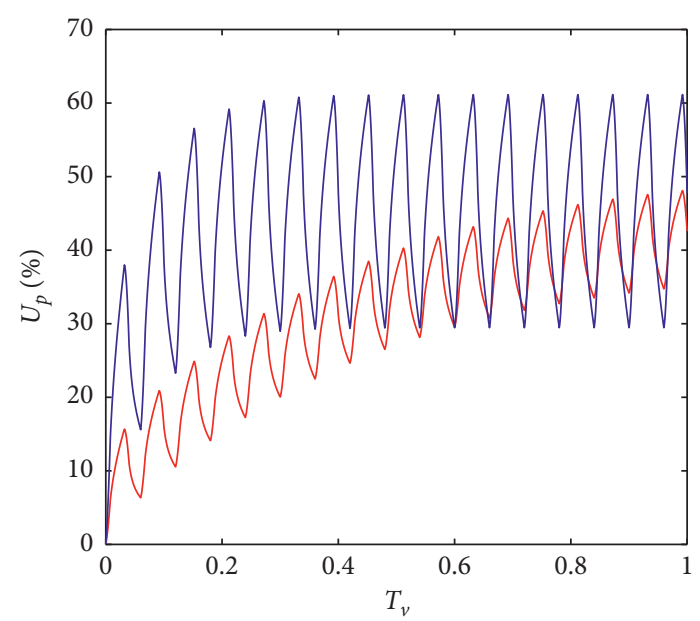

- Single drainage

_ Double drainage

(a)

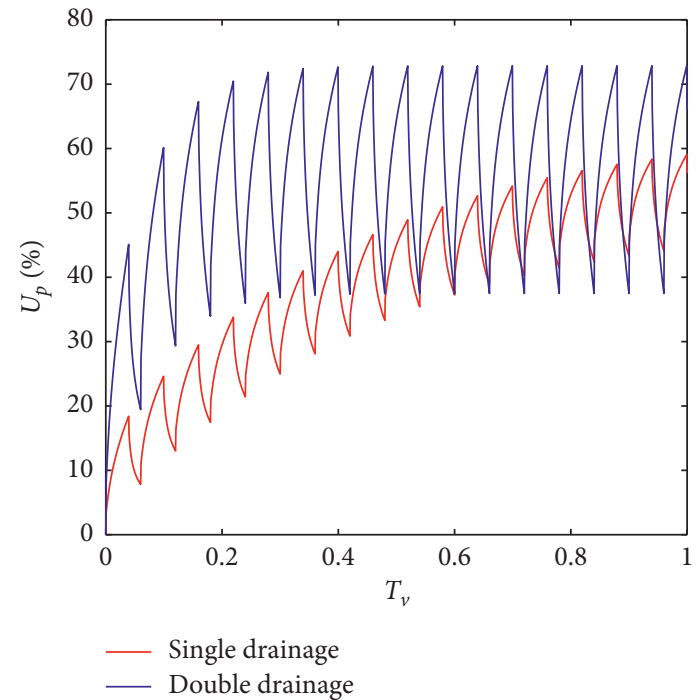

(b)

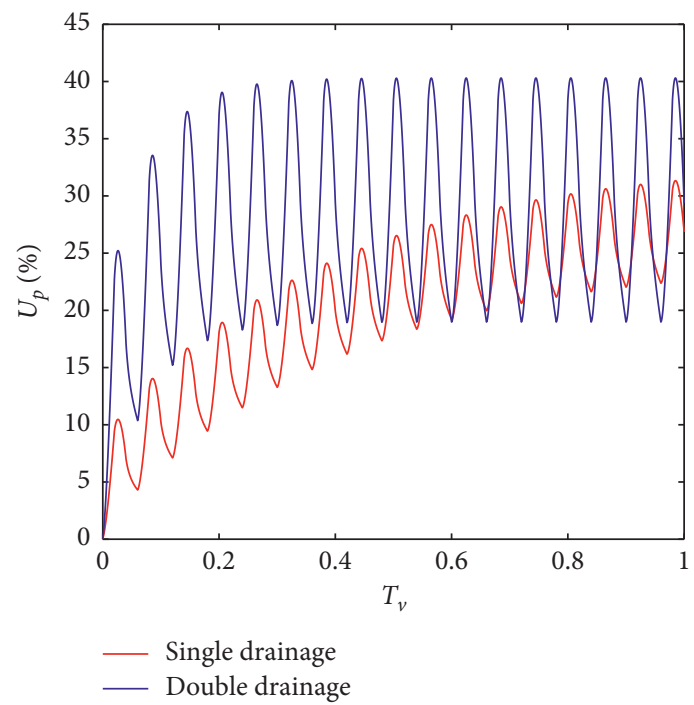

(c)

FIGURE 12: The variations of average degrees of consolidation $U_{s}$ and $U_{p}$ with time factor $T_{v}$ under different drainage conditions. 

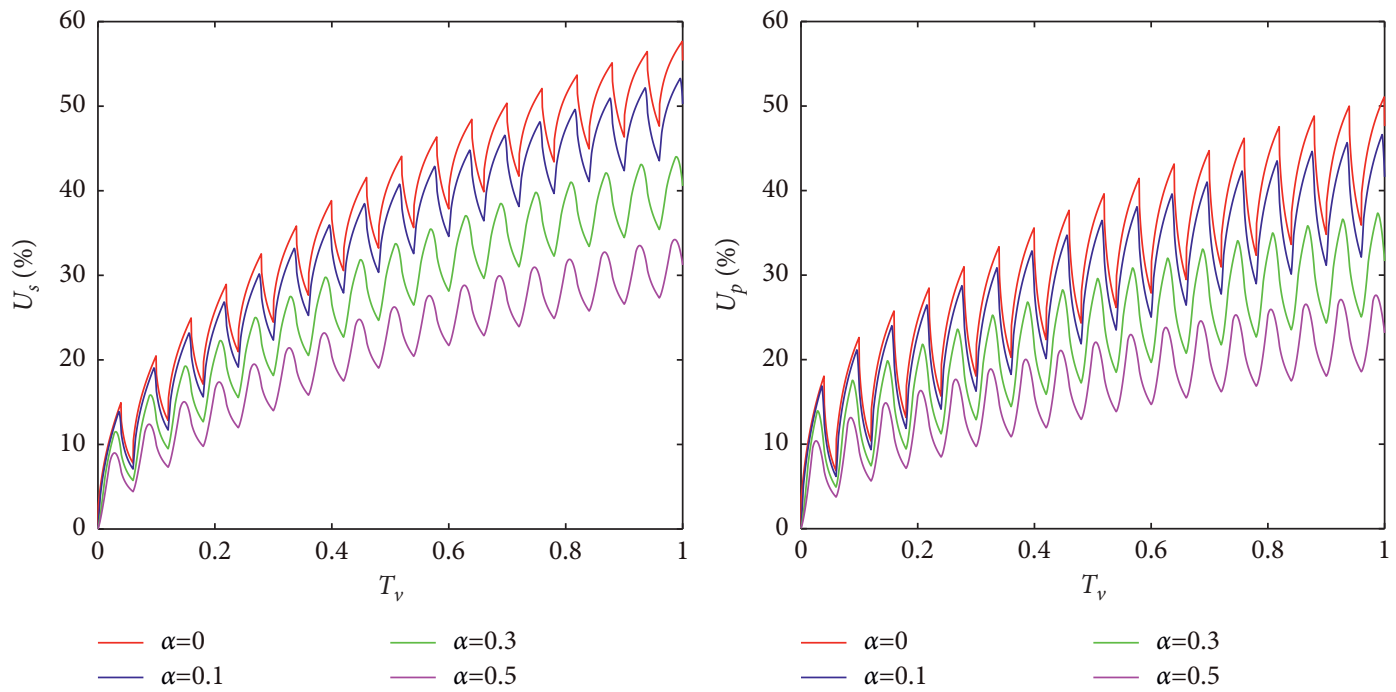

Figure 13: The variations of average degrees of consolidation $U_{s}$ and $U_{p}$ with time factor $T_{v}$ under different values of $\alpha$.
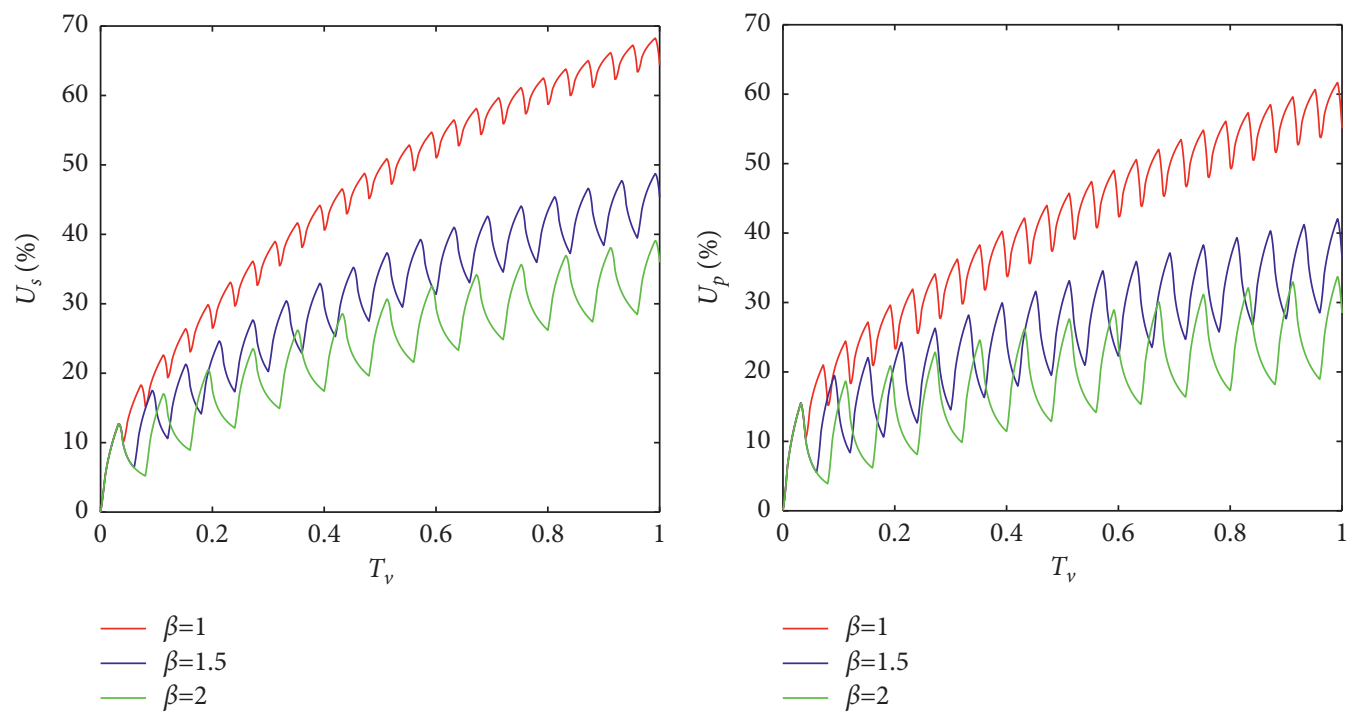

(a)
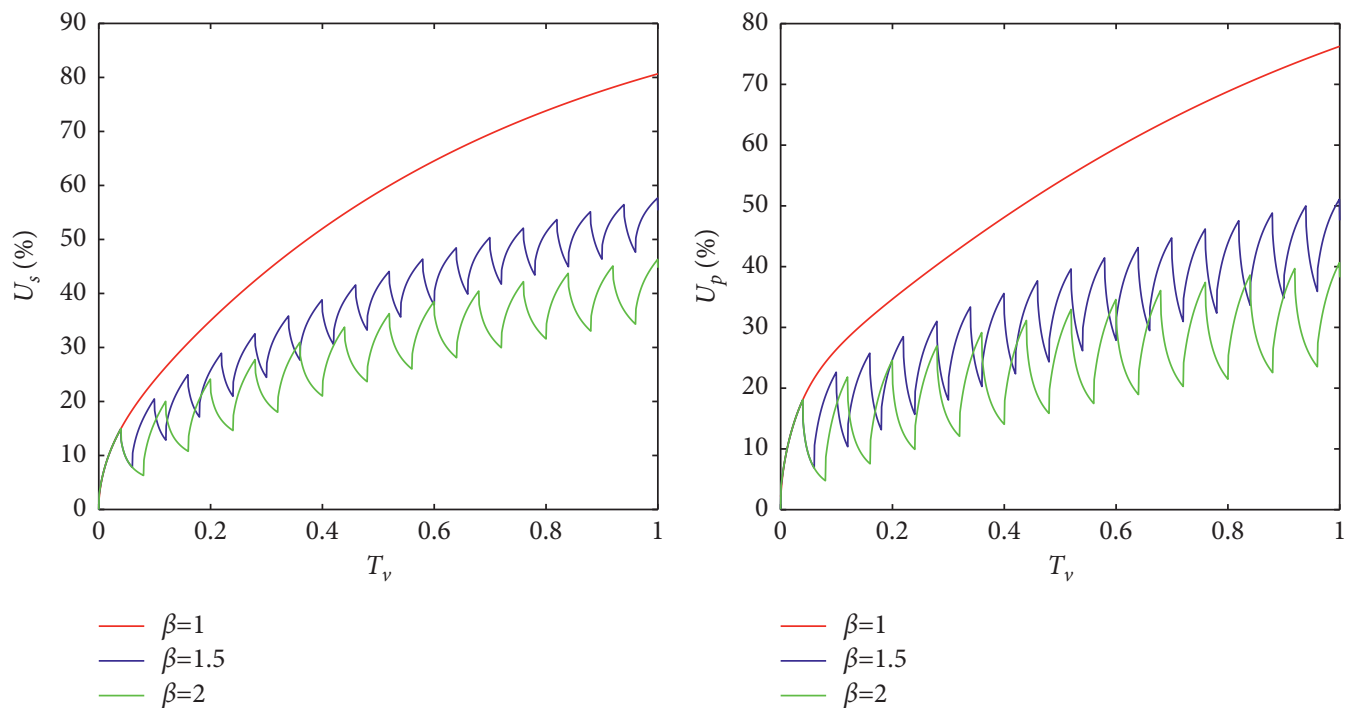

(b)

Figure 14: Continued. 

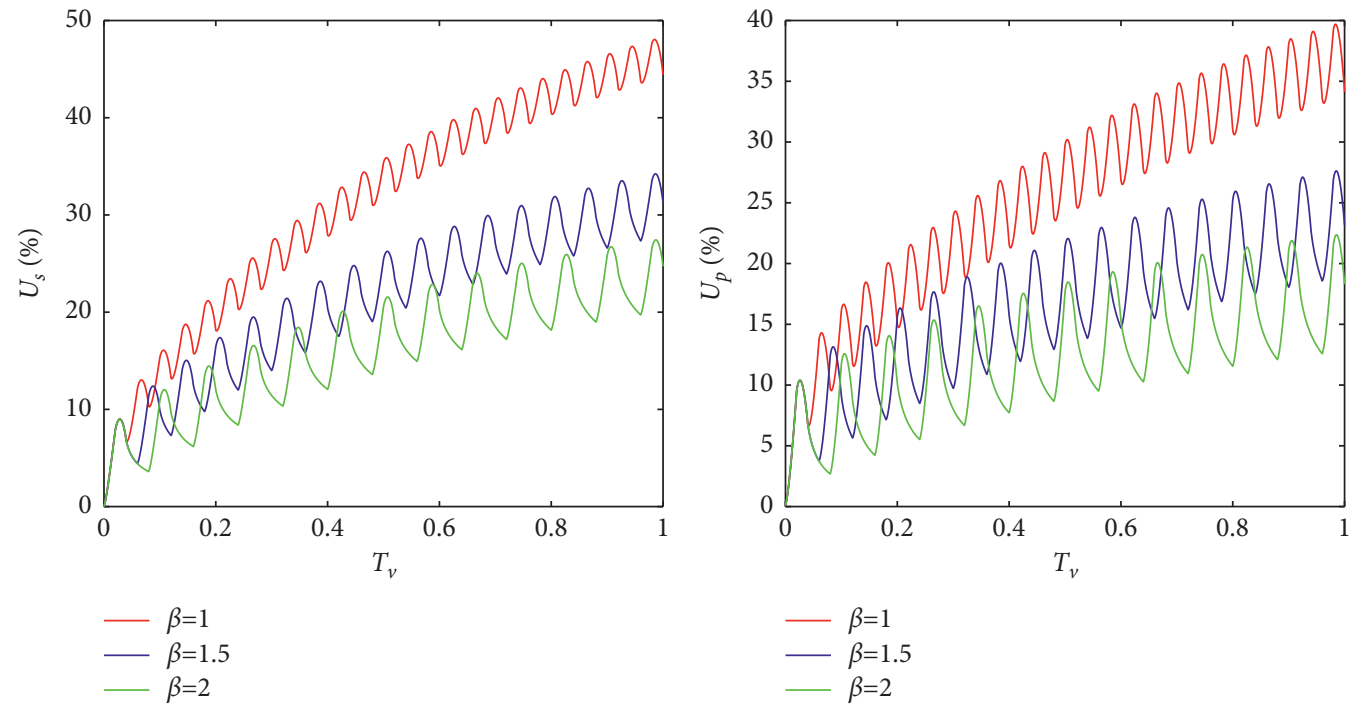

(c)

Figure 14: The variations of average degrees of consolidation $U_{s}$ and $U_{p}$ with time factor $T_{v}$ under different values of $\beta$.
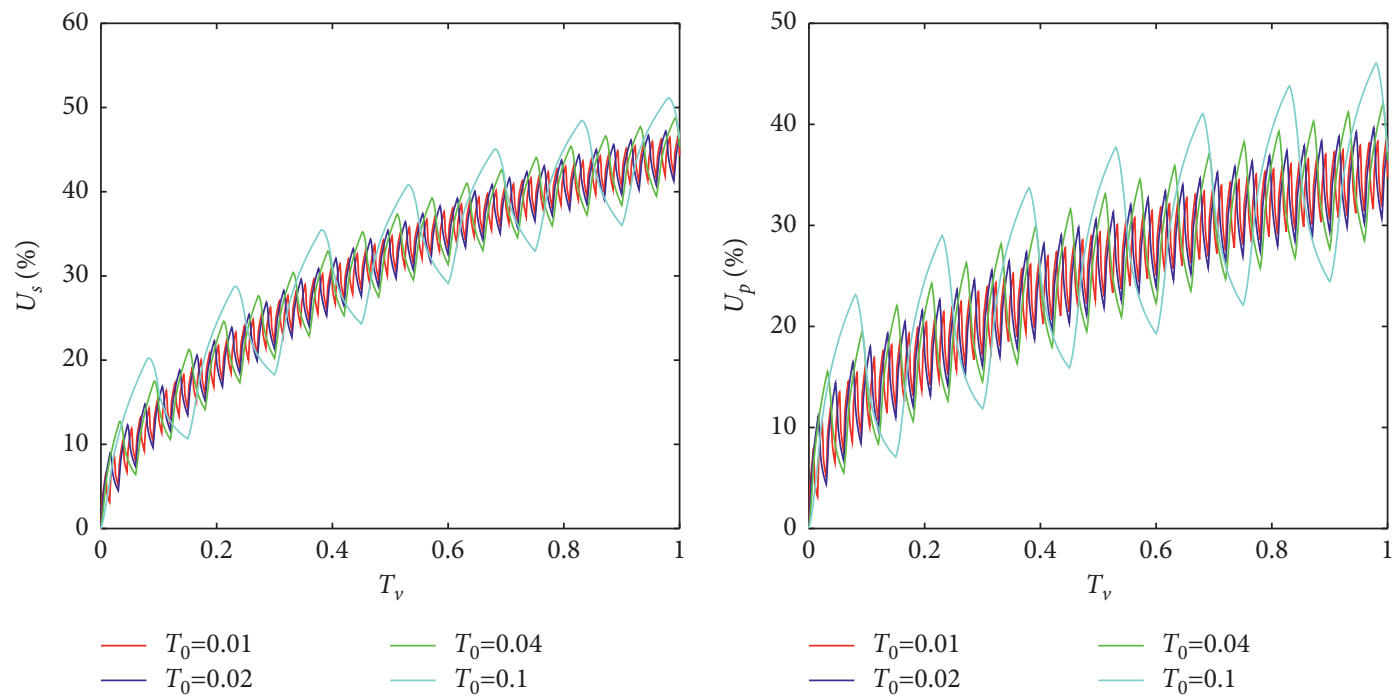

(a)
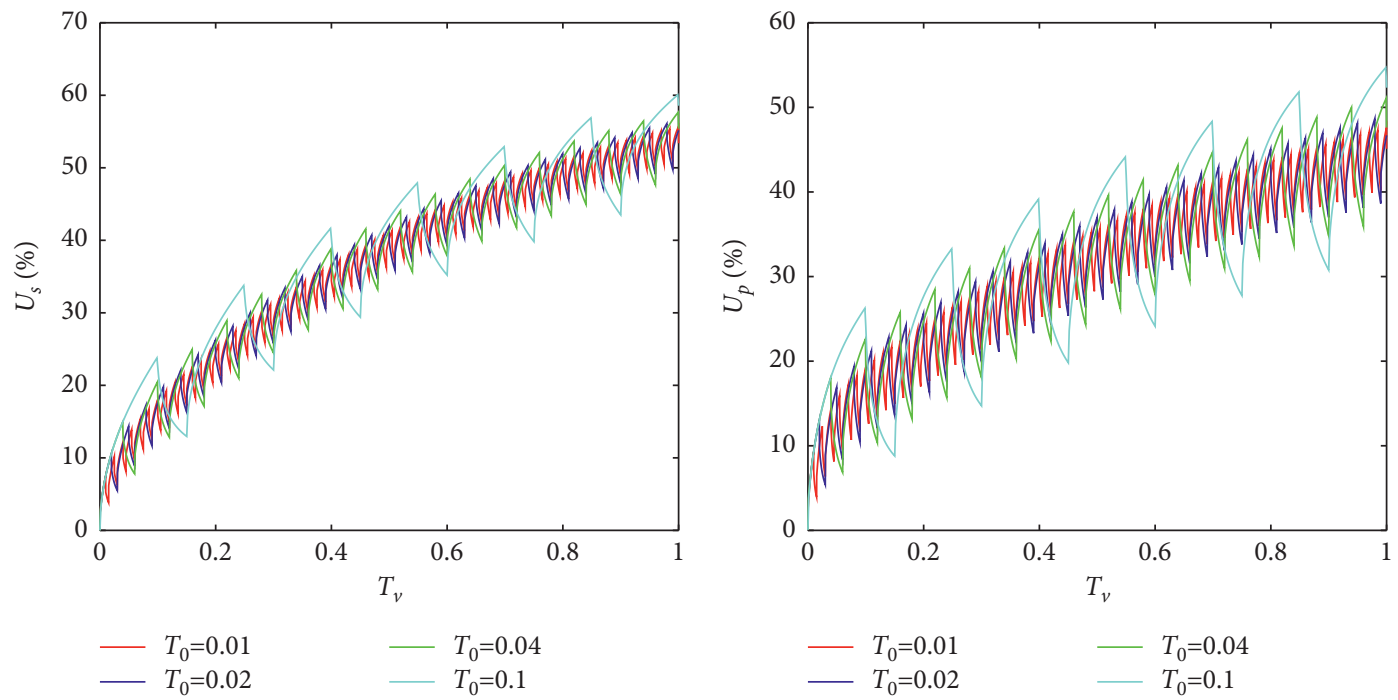

(b)

FIgURE 15: Continued. 

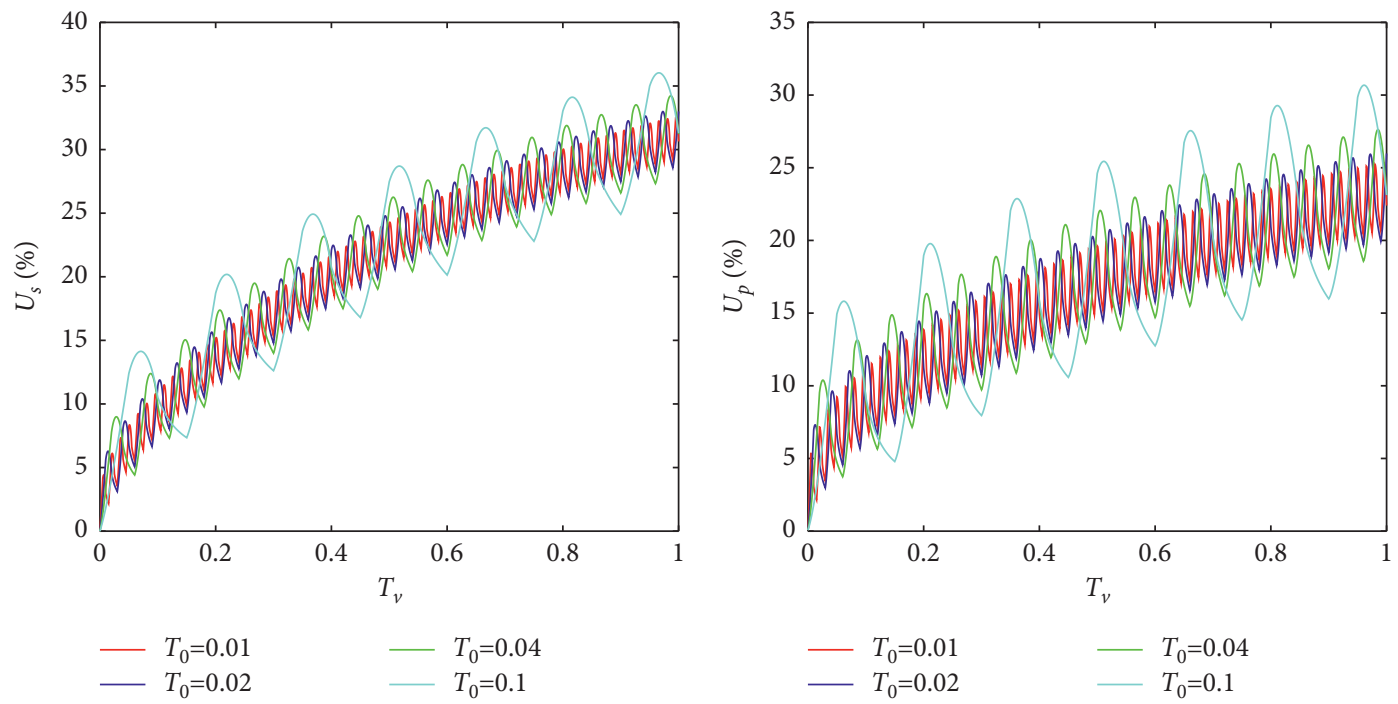

(c)

Figure 15: The variations of average degrees of consolidation $U_{s}$ and $U_{p}$ with time factor $T_{v}$ under different values of $T_{0}$.

\section{Conclusion}

In this paper, analytical solutions have been presented for $1 \mathrm{D}$ nonlinear consolidation of saturated double-layered soil subjected to cyclic loadings such as trapezoidal cyclic loading, rectangular cyclic loading, and triangular cyclic loading. It shows through the degeneration of the proposed solutions into special cases that the solutions presented in this paper are more general for the nonlinear consolidation of saturated soils under time-dependent loading. Based on the proposed solutions, a comprehensive parametric study is conducted, and the following conclusions can be drawn:

(1) The nonlinear consolidation of saturated double-layered soil under cyclic loadings is affected by layer parameters such as the permeability ratio, the compressibility ratio, and the thickness ratio. The smaller permeability of the lower layer decreases the rates of settlement and dissipation of excess pore pressure. An increase in the compressibility of the lower layer will decrease the rate of consolidation. Furthermore, the rate of settlement increases when the thickness of the lower layer with higher compressibility decreases.

(2) The drainage conditions have great effects on the nonlinear consolidation behavior of saturated double-layered soil under cyclic loadings. The rates of settlement and dissipation of excess pore pressure and the amplitudes of fluctuation in the rates for a double drainage condition are bigger than those for a single drainage condition.

(3) The loading parameters have significant influences on the nonlinear consolidation behavior of saturated double-layered soil subjected to various cyclic loadings. The greater the rate of increment or decrement of loading, the greater the rate of consolidation. The rate of consolidation under cyclic loadings increases with the decrease of the rest period of cyclic loadings. The longer the period of loading, the bigger amplitude and less cycles of fluctuation in the settlement rate and the dissipation rate of excess pore pressure.

\section{Appendix}

\section{A. The Derivation of General Solutions for $\omega_{i}$}

The general solutions of equation (4) for a single drainage condition can be assumed as follows:

$$
\omega_{i}=\sum_{m=1}^{\infty} g_{m i}(z) e^{-\beta_{m} t}\left[B_{m}+C_{m} T_{m}(t)\right], \quad(i=1,2),
$$

where $\quad g_{m 1}(z)=\sin \left(\lambda_{m} z / h_{1}\right), g_{m 2}(z)=A_{m} \cos \left(\mu \lambda_{m}(H\right.$ $\left.\left.-z / h_{1}\right)\right) ; \beta_{m}, \mu, \lambda_{m}, A_{m}, B_{m}$, and $C_{m}$ are unknown coefficients to be found; and $T_{m}(t)$ is a function of $t$, resulting from $R(t)$.

Substituting equation (10) into the boundary condition equation (8), we can get $A_{m}$ as follows:

$$
A_{m}=\frac{\sin \left(\lambda_{m}\right)}{\cos \left(\mu c \lambda_{m}\right)}
$$

where

$$
c=\frac{h_{2}}{h_{1}}
$$

Substituting equation (10) into (4) and simplifying, $\beta_{m}$ and $\mu$ can be obtained as follows: 


$$
\begin{gathered}
\beta_{m}=\frac{c_{v}^{1} \lambda_{m}^{2}}{h_{1}^{2}}, \\
\mu=\sqrt{\frac{c_{v}^{1}}{c_{v}^{2}}} .
\end{gathered}
$$

In order to determine $\lambda_{m}$, the eigen equation can be obtained by substituting equation (10) into the boundary condition equation (9) as follows:

$$
\mu K \tan \left(\lambda_{m}\right) \tan \left(\mu c \lambda_{m}\right)=1 .
$$

Furthermore, using the coefficients obtained above, we can get the following relations:

$$
\begin{aligned}
T_{m}(t) & =\int_{0}^{t} e^{\beta_{m} \tau} R(\tau) d \tau, \\
\sum_{m=1}^{\infty} C_{m} g_{m i}(z) & =1, \quad(i=1,2), \\
\sum_{m=1}^{\infty} B_{m} g_{m i}(z) & =\omega_{0}, \quad(i=1,2),
\end{aligned}
$$

Using the following orthogonal relation,

$$
\int_{0}^{h_{1}} g_{m 1}(z) g_{n 1}(z) \mathrm{d} z+\mu^{2} K \int_{h_{1}}^{H} g_{m 2}(z) g_{n 2}(z) \mathrm{d} z= \begin{cases}0, & m \neq n, \\ \frac{1}{2}, & h_{1}\left(1+\mu^{2} \mathrm{KcA}_{m}^{2}\right), m=n,\end{cases}
$$

$B_{m}$ and $C_{m}$ can be written as follows:

$B_{m}=\frac{\int_{0}^{h_{1}} g_{m 1}(z) \mathrm{d} z+\mu^{2} K \int_{h_{1}}^{H} g_{m 2}(z) \mathrm{d} z}{\int_{0}^{h_{1}} g_{m 1}^{2}(z) \mathrm{d} z+\mu^{2} K \int_{h_{1}}^{H} g_{m 2}^{2}(z) \mathrm{d} z} \omega_{0}=\frac{2 \omega_{0}}{\lambda_{m}\left(1+\mu^{2} \mathrm{KcA}_{m}^{2}\right)}$,

$C_{m}=\frac{\int_{0}^{h_{1}} g_{m 1}(z) \mathrm{d} z+\mu^{2} K \int_{h_{1}}^{H} g_{m 2}(z) \mathrm{d} z}{\int_{0}^{h_{1}} g_{m 1}^{2}(z) \mathrm{d} z+\mu^{2} K \int_{h_{1}}^{H} g_{m 2}^{2}(z) \mathrm{d} z}=\frac{2}{\lambda_{m}\left(1+\mu^{2} \mathrm{KcA}_{m}^{2}\right)}$.
Now, substituting all those coefficients into equation (10), the general solutions of equation (4) for a single drainage condition can be written as follows:

$$
\begin{aligned}
& \omega_{1}=\sum_{m=1}^{\infty} \sin \left(\lambda_{m} \frac{z}{h_{1}}\right) e^{-\beta_{m} t}\left[B_{m}+C_{m} \int_{0}^{t} e^{\beta_{m} \tau} R(\tau) \mathrm{d} \tau\right], \\
& \omega_{2}=\sum_{m=1}^{\infty} A_{m} \cos \left(\mu \lambda_{m} \frac{H-z}{h_{1}}\right) e^{-\beta_{m} t}\left[B_{m}+C_{m} \int_{0}^{t} e^{\beta_{m} \tau} R(\tau) \mathrm{d} \tau\right] .
\end{aligned}
$$

Similarly, the general solutions of equation (4) for a double drainage condition can be obtained as follows:

$$
\begin{aligned}
& \omega_{1}=\sum_{m=1}^{\infty} \sin \left(\lambda_{m} \frac{z}{h_{1}}\right) e^{-\beta_{m} t}\left[B_{m}+C_{m} \int_{0}^{t} e^{\beta_{m} \tau} R(\tau) \mathrm{d} \tau\right], \\
& \omega_{2}=\sum_{m=1}^{\infty} A_{m} \sin \left(\mu \lambda_{m} \frac{H-z}{h_{1}}\right) e^{-\beta_{m} t}\left[B_{m}+C_{m} \int_{0}^{t} e^{\beta_{m} \tau} R(\tau) \mathrm{d} \tau\right],
\end{aligned}
$$


where

$$
A_{m}=\frac{\sin \left(\lambda_{m}\right)}{\sin \left(\mu c \lambda_{m}\right)} .
$$

The eigen equation for $\lambda_{m}$ can be obtained as follows:

$$
\begin{gathered}
-\mu K \tan \left(\lambda_{m}\right) \cot \left(\mu c \lambda_{m}\right)=1, \\
B_{m}=\frac{2\left(1+\mu K A_{m}\right) \omega_{0}}{\lambda_{m}\left(1+\mu^{2} \mathrm{KcA}_{m}^{2}\right)} \\
C_{m}=\frac{2\left(1+\mu K A_{m}\right)}{\lambda_{m}\left(1+\mu^{2} \mathrm{KcA}_{m}^{2}\right)} .
\end{gathered}
$$

\section{Data Availability}

The data used to support the findings of this study are included within the article.

\section{Conflicts of Interest}

The authors declare that there are no conflicts of interest.

\section{References}

[1] N. E. Wilson and M. M. Elgohary, "Consolidation of soils under cyclic loading," Canadian Geotechnical Journal, vol. 11, no. 3, pp. 420-423, 1974.

[2] S. S. Razouki and T. Schanz, "One-dimensional consolidation under haversine repeated loading with rest period," Acta Geotechnica, vol. 6, no. 1, pp. 13-20, 2011.

[3] S. S. Razouki, P. Bonnier, M. Datcheva, and T. Schanz, "Analytical solution for 1D consolidation under haversine cyclic loading," International Journal for Numerical and Analytical Methods in Geomechanics, vol. 37, no. 14, pp. 2367-2372, 2013.

[4] P. Kim, Y.-G. Kim, C.-H. Paek, and J. Ma, "Lattice Boltzmann method for consolidation analysis of saturated clay," Journal of Ocean Engineering and Science, vol. 4, no. 3, pp. 193-202, 2019.

[5] M. Favaretti and M. Soranzo, "A simplified consolidation theory in cyclic loading conditions," Journal of Applied Sciences, vol. 8, pp. 405-409, 1995.

[6] E. Conte and A. Troncone, "One-dimensional consolidation under general time-dependent loading," Canadian Geotechnical Journal, vol. 43, no. 11, pp. 1107-1116, 2006.

[7] M. M. Baligh and J. N. Levadoux, "Consolidation theory for cyclic loading," Journal of the Geotechnical Engineering Division, vol. 104, no. 4, pp. 415-431, 1978.

[8] M. M. Toufigh and A. Ouria, "Consolidation of inelastic clays under rectangular cyclic loading," Soil Dynamics and Earthquake Engineering, vol. 29, no. 2, pp. 356-363, 2009.

[9] E. H. Davis and G. P. Raymond, "A non-linear theory of consolidation," Géotechnique, vol. 15, no. 2, pp. 161-173, 1965.

[10] K.-H. Xie, T. Qi, and Y.-Q. Dong, "Nonlinear analytical solution for one-dimensional consolidation of soft soil under cyclic loading," Journal of Zhejiang University-SCIENCE A, vol. 7, no. 8, pp. 1358-1364, 2006.

[11] E. Conte and A. Troncone, "Nonlinear consolidation of thin layers subjected to time-dependent loading," Canadian Geotechnical Journal, vol. 44, no. 6, pp. 717-725, 2007.
[12] D. Cheng, W. Wang, X. Chen, and Z. Zhang, "Finite analytic method for one-dimensional nonlinear consolidation under time-dependent loading," Shock and Vibration, vol. 2017, Article ID 4071268, 12 pages, 2017.

[13] P. Kim, Y. G. Kim, H. B. Myong, C. H. Paek, and J. Ma, "Numerical analysis for nonlinear consolidation of saturated soil using lattice Boltzmann method," International Research Journal of Engineering and Technology, vol. 6, no. 4, pp. 3611-3618, 2019.

[14] X. Geng, C. Xu, and Y. Cai, "Non-linear consolidation analysis of soil with variable compressibility and permeability under cyclic loadings," International Journal for Numerical and Analytical Methods in Geomechanics, vol. 30, no. 8, pp. 803-821, 2006.

[15] Y.-Q. Cai, X.-Y. Geng, and C.-J. Xu, "Solution of one-dimensional finite-strain consolidation of soil with variable compressibility under cyclic loadings," Computers and Geotechnics, vol. 34, no. 1, pp. 31-40, 2007.

[16] P. Kim, K. S. Ri, Y. G. Kim, K. N. Sin, H. B. Myong, and C. H. Paek, "Nonlinear consolidation analysis of a saturated clay layer with variable compressibility and permeability under various cyclic loadings," International Journal of Geomechanics, vol. 20, p. 1730, 2020.

[17] H. Gray, "Simultaneous consolidation of contiguous layers of unlike compressive soils," ASCE Trans, vol. 110, pp. 13271356, 1945.

[18] R. L. Schiffman and J. R. Stein, "One-dimensional consolidation of layered systems," Journal of the Soil Mechanics and Foundations Division, vol. 96, no. 4, pp. 1499-1504, 1970.

[19] P. K. K. Lee, K. H. Xie, and Y. K. Cheung, "A study on onedimensional consolidation of layered systems," International Journal for Numerical and Analytical Methods in Geomechanics, vol. 16, no. 11, pp. 815-831, 1992.

[20] K. H. Xie and Q. Y. Pan, "Theory of one-dimensional consolidation of layered soils under variable loading," Chinese Journal of Geotechnical Engineering, vol. 17, no. 5, pp. 82-87, 1995.

[21] J. Huang and D. V. Griffiths, "One-dimensional consolidation theories for layered soil and coupled and uncoupled solutions by the finite-element method," Géotechnique, vol. 60, no. 9, pp. 709-713, 2010.

[22] K.-H. Xie, X.-Y. Xie, and W. Jiang, "A study on one-dimensional nonlinear consolidation of double-layered soil," Computers and Geotechnics, vol. 29, no. 2, pp. 151-168, 2002.

[23] R. P. Chen, W. H. Zhou, H. Z. Wang, and Y. M. Chen, "Onedimensional nonlinear consolidation of multi-layered soil by differential quadrature method," Computers and Geotechnics, vol. 32, no. 5, pp. 358-369, 2005.

[24] J. Hu, X. Bian, and Y. Chen, "Nonlinear consolidation of multilayer soil under cyclic loadings," European Journal of Environmental and Civil Engineering, vol. 25, no. 6, pp. 1042-1064, 2019. 